\title{
What Happened with Spectrometer Magnet 2B
}

\author{
Michael A. Green \\ Lawrence Berkeley National Laboratory
}

27 May 2010

\begin{abstract}
The spectrometer solenoid is supposed to be the first magnets installed in MICE [1],[4]. This report described what happened during the test of the MICE spectrometer solenoid 2B. First, the report describes the temperatures in the magnet, the cooler top plate and the shield during the run where the magnet quenched at $258 \mathrm{~A}$. During this quench, a lead between the bottom of the HTS leads and the diode bank burned out causing the magnet to quench. Second, three methods for measuring the net heat flow into the cold mass are described. Third, there is a discussion of possible resistive heating in the HTS leads between liquid helium temperature and the copper plate, which is at about $50 \mathrm{~K}$. Fourth, there is a discussion of the measured first stage heat loads in the magnet, when there is no current in the magnet. The first stage heat load calculations are based on knowing the first stage temperatures of the three two-stage pulse tube coolers and the single stage GM cooler. Fifth, the estimated heat load to the first stage when the magnet has current in it is discussed. Sixth, there is a comparison of the stage 1 heat loads in magnet 1A [5], magnet 2A [6], and magnet 2B [7]. Finally there is a discussion of recommended changes for improving the spectrometer solenoids so that the coolers can keep them cold.
\end{abstract}

\section{Table of Contents}

$\begin{array}{lc}\text { Abstract } & 1 . \\ \text { Table of Contents } & 1 . \\ \text { Introduction } & 2 . \\ \text { Conditions that may have led to the M2 Coil Lead Break } & 5 . \\ \text { Magnet Calorimetric Measurements of the Net Heat Flow at 4 K } & 7 . \\ \text { Resistive Heating in the HTS Leads, Is this real? } & 10 . \\ \text { Measured Cooler First-stage Heat Loads with No Current in the Magnet } & 11 . \\ \text { Estimated Cooler First-stage Heat Loads with Current in the Magnet } & 13 . \\ \text { A Comparison of Magnet 2B, with Magnet 2A and Magnet 1A } & 15 . \\ \text { Thermal Network Diagrams for Magnet 1A, Magnet 2A and Magnet 2B } & 20 . \\ \text { Recommended Changes for Improving the Spectrometer Solenoid } & 23 . \\ \text { Acknowledgment } & 24 . \\ \text { References } & 24 .\end{array}$




\title{
What Happened with Spectrometer Magnet 2B
}

\author{
Michael A. Green \\ Lawrence Berkeley National Laboratory
}

\begin{abstract}
Introduction
The second version of Magnet 2 (called magnet 2B in this report) was tested between 15 March and 31 March 2010. The cool-down of the magnet was successful. The magnet had a number of training quenches starting at $169 \mathrm{~A}$. The first low current quench was believed to be due to power supply issues. On 19 March 2010, the five coils in series were trained to a current of 258 A (94\% of the magnet design current). During this quench, one of the low temperature superconducting leads for coil M2 burned out or was disconnected. The break in the lead occurred between the voltage tap inside of the cold mass (near the diodes) and the bottom of the HTS lead. It is not clear whether the quench was caused by the lead break or whether the quench caused the lead break. The liquid level in the magnet cryostat during the quench test was low (less than zero on the upper level gauge). The magnet cryostat was about half full. Depending on the location of the lead break, the fact that the liquid level was low may have been a contributory factor in the break of the M2 lead.

The three-coil set (E1, center, and E2) was subsequently quenched at a current of 270 A. (This is $\sim 99 \%$ of the design current for the three coil set.) After the three coil set was quenched at $270 \mathrm{~A}$, the magnet cryostat was completely filled up. The magnet cryostat was kept full during the period of time that the people from LBNL were at the MICE collaboration meeting in Riverside. From 20:25 on 22 March until 8:50 on 29 March about 250 liters of helium were boiled away, at an average cryostat pressure of 1.17 bar. The average boil-off rate during the period of 156.4 hours was between 1.58 and 1.68 liters per hour. During this period, the tank was always kept at least half full. During one 45.3-hour period of time between 74 and 80 liters were boiled away (depending on whether the cryostat was filled above the top level gauge). During this period the helium boil-off rate was from 1.63 to 1.77 liters per hour (at a cryostat pressure of 1.15 bar). During the period from March $25^{\text {th }}$ to March $29^{\text {th }}$, there was no current in any coils the magnet.

Calorimetric tests were done 30 March 2010 when the magnet cryostat was overfilled (into the manifold between the coolers and the cold mass). Once the magnet cryostat was filled, the magnet was charged at the rate of $0.06 \mathrm{~A} \mathrm{~s}^{-1}$. The calorimetric test was done with the vent valve closed. The temperature and pressure of the helium in the tank were measured. From these measurements, the heat flow into the cryostat was determined. During the charging of the three coils in series, the three coil set quenched at 253 A (93 percent of its design current). The cryostat was then filled to about half full. In the twelve hour period from 21:40 on 30 March to 9:50 on 31 March 31 liters of helium were boiled away. During this period the boil-off rate appeared to be $\sim 2.5$ liters per hour. On 31 March, calorimetric tests were done by measuring the helium boil off from the tank using a positive displacement gas meter. During this test the cryostat pressure was set at $1.27 \mathrm{bar}$ and the helium cryostat was about one-quarter full. This was the most accurate calorimetric data taken during any of the magnet tests.
\end{abstract}


This report will look at three aspects of the spectrometer magnet test. First, the conditions that led to the break of the coil M2 lead will be presented. Second, the most accurate cryostat heat leak data will be analyzed. Finally, the temperatures and heat loads will be analyzed for the test of magnet 1 (magnet test $1 \mathrm{~A}$ ) and the two tests of magnet 2 (magnet tests $2 \mathrm{~A}$ and $2 \mathrm{~B}$ ). In the case of magnet $2 \mathrm{~B}$, we had measurements of the temperatures of stage- 1 and stage- 2 of the four coolers. From this data and the calorimetric data one can determine the heat load into both stages of the cooler. From data taken during the cooler and lead test, we will estimate the heat loads into the first stages of the three coolers in magnets $1 \mathrm{~A}$ and $2 \mathrm{~A}$. For both magnets $1 \mathrm{~A}$ and magnet $2 \mathrm{~A}$, we have statements from the vendor concerning measurements of net boil-off he did in both of these tests, but no direct observations. We will explore the validity of the estimates of the stage 2 heat loads into the three coolers during tests of magnet $1 \mathrm{~A}$ and 2A.

Before describing the three aspects of the spectrometer magnet tests, it is useful to look at the operating diagram for a Cryomech PT415 pulse tube cooler. The operating diagram shown in Figure 1 plots the cooler operating points on a diagram with the cooler first-stage temperature $\mathrm{T} 1$ on the $\mathrm{x}$-axis and the second-stage temperature $\mathrm{T} 2$ on the $\mathrm{y}$ axis. Each point on the diagram represents a particular value of the first-stage heat load $\mathrm{Q} 1$ and the second stage heat load Q2. The Q1 points are for values of Q1 of 0, $21 \mathrm{~W}, 42$ $\mathrm{W}, 63 \mathrm{~W}$ and $84 \mathrm{~W}$. The Q2 points are for values of Q2 of $0,0.5 \mathrm{~W}, 1.0 \mathrm{~W}, 1.5 \mathrm{~W}, 2.0$ $\mathrm{W}, 2.5 \mathrm{~W}$ and $3.0 \mathrm{~W}$. Tom Painter's group at Florida State University took the data shown in Figure 1 [8] [9].

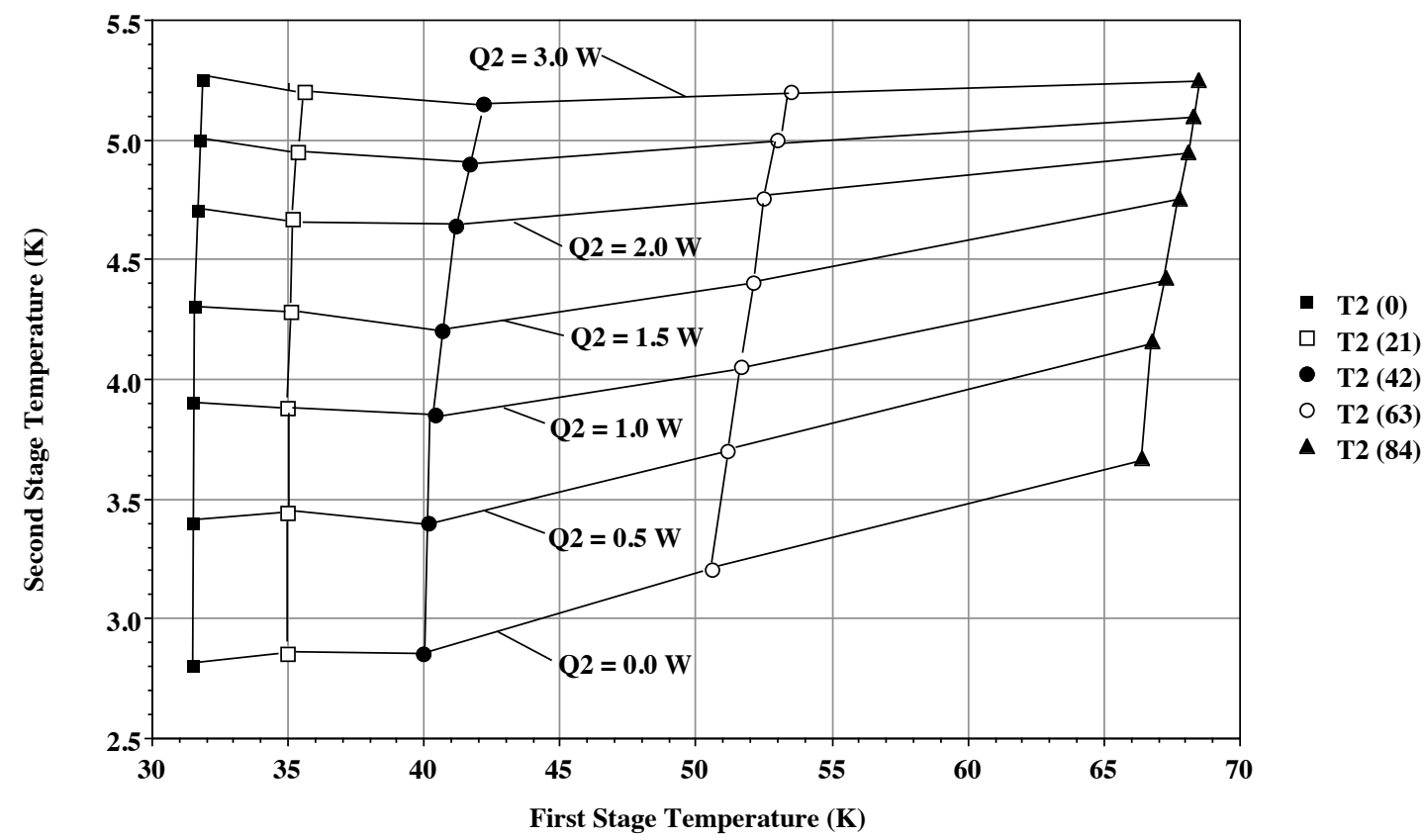

Figure 1. Operating temperature diagram for the first-stage temperature $\mathrm{T} 1$ and the second-stage temperature T2 of a PT415 pulse tube cooler as a function of the first-stage heat load Q1 and the second-stage heat load Q2. (Data taken by Florida State University.) 
From Figure 1, it is clear that at low values of the stage-1 heat load Q1 $(<42 \mathrm{~W})$, the effect of the stage-2 heat load Q2 on stage-1 is relatively small. As the heat load into stage- 1 increases, the effect of the stage- 2 heat load on the first-stage temperature becomes more pronounced. At stage-1 heat loads Q1 above $42 \mathrm{~W}$, the stage-2 temperature T2 goes up for a given stage-2 heat load Q2. The diagram shown in Figure 1 shows the importance of keeping the cooler first stage temperature low (below $45 \mathrm{~K}$ ). It appears that the PT415 cooler performance is optimum for a first-stage heat load of about $42 \mathrm{~W}$. Similar behavior has been observed on the Cryomech PT410 pulse tube cooler and various two-stage GM coolers made by Sumitomo and others. The PT415 cooler operating diagram shown in Figure 1 is still expected to apply in the United Kingdom, where the power frequency is $50 \mathrm{~Hz}$ rather than the $60 \mathrm{~Hz}$ corresponding to the data in Figure 1. This is true provided the cooler hose is charged to the correct pressure for the operating frequency. The reason for this is that the rotating valve frequency is independent of the $\mathrm{AC}$ electric power frequency. Thus, the pulsing frequency is the same for $50 \mathrm{~Hz}$ power as it is for $60 \mathrm{~Hz}$ power.

Figure 2 shows the location of temperature sensors, voltage taps and liquid helium level gauges in magnet $2 \mathrm{~B}$ [10]. There was similar instrumentation installed on magnet 1 A (the version of magnet 1 that was tested in 2008). The temperature sensors are of three different types. There are platinum resistance temperature sensors TPR, which are good down to $28 \mathrm{~K}$, silicon diode temperature sensors TSD, which are good over the whole temperature range, and Cernox temperature sensors TRX, which are also good over the whole temperature range. The platinum resistance sensors and Cernox temperature sensors are quite accurate (to $\pm 0.03 \mathrm{~K}$ ) if they are properly calibrated. The silicon diode sensors were un-calibrated and, as a result, they are accurate only to $\pm 0.4 \mathrm{~K}$. The platinum resistor sensors and the silicon diodes have a general calibration curve that can be applied. Cernox sensors must be individually calibrated, so large errors result if the wrong calibration curve is used. There are voltage taps in the helium vessel VTM01-09, at the bottom of the HTS leads VTL09-16, and at the tops of the HTS leads VTL01-08. The two helium level gauges cover about $75 \%$ of the helium vessel. These gauges are highly nonlinear in terms of the reading versus liquid volume.

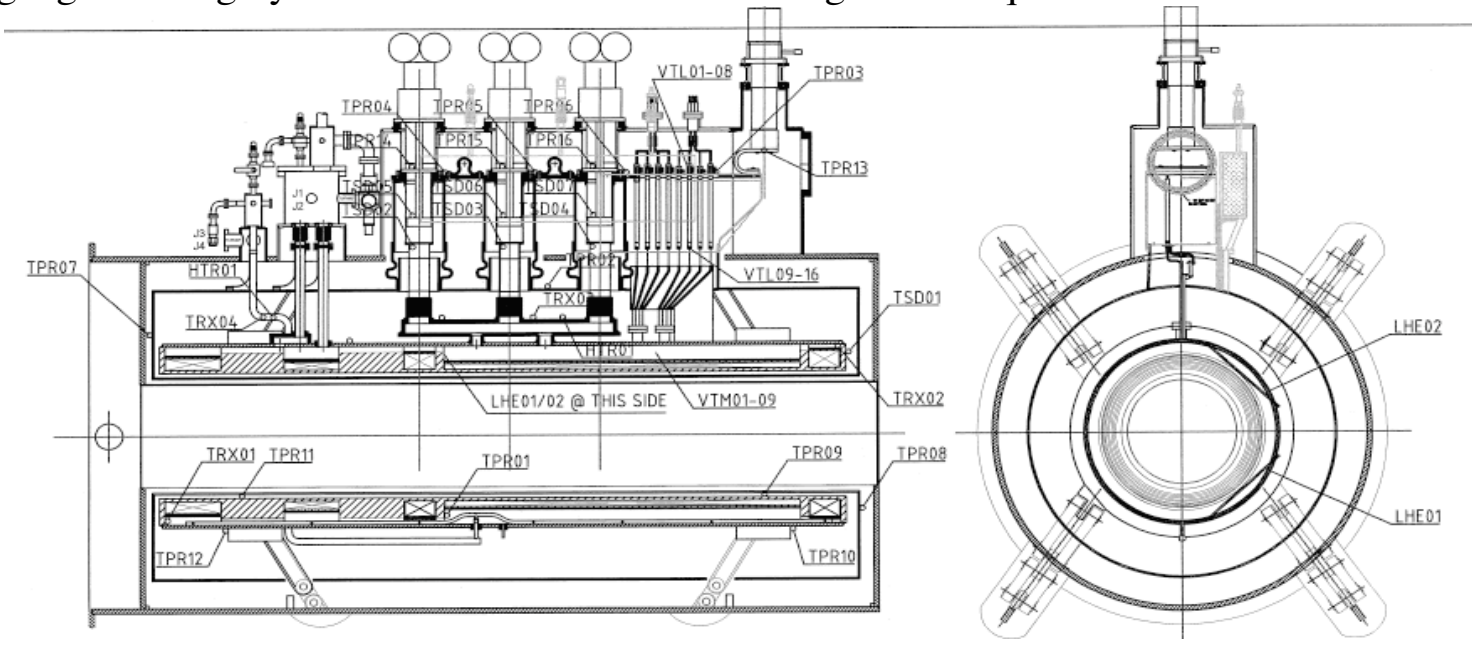

Figure 2. Location of temperature sensors, voltage taps and level gauges on magnet 2B. 


\section{Conditions that may have led to the M2 Coil Lead Break}

Table 1 shows the temperatures and liquid levels in the cryostat just before the quench at $258 \mathrm{~A}$ that resulted in the break of the lead between the bottom of the HTS lead and the voltage tap to the coil. This quench occurred on 19 March 2010. The interpretation of the data given in Table 1 depends on where the lead break occurred.

Table 1. Temperature and liquid level data during the magnet charge of 19 March 2010.

\begin{tabular}{|l|c|c|c|}
\hline Time on 19 March 2010 (PST) & $\sim 15: 20$ & $\sim 15: 45$ & $\sim 16: 16$ \\
\hline Current in the Five Coils (A) & $\sim 140$ & $\sim 212$ & $\sim 250$ \\
\hline Cu Plate T at far end of Leads TPR3 (K) & $\mathbf{4 5 . 4 5}$ & $\mathbf{4 6 . 6 3}$ & $\mathbf{4 8 . 1 7}$ \\
\hline Cu Plate T near Cooler 1 TPR4 (K) & $\mathbf{5 0 . 5 3}$ & $\mathbf{5 0 . 4 9}$ & $\mathbf{5 0 . 7 5}$ \\
\hline Cu Plate T near Cooler 2 TPR5 (K) & No data & No data & No data \\
\hline Cu Plate T near Cooler 3 TPR6 (K) & $\mathbf{4 8 . 8 2}$ & $\mathbf{4 9 . 3 8}$ & $\mathbf{5 0 . 4 7}$ \\
\hline Shield T M1 End at Top TPR7 (K) & 87.87 & 87.42 & 87.22 \\
\hline Shield T E2 End at bottom TPR8 (K) & 98.55 & 98.51 & 98.45 \\
\hline T Outside of Cold Mass at E2 End TSD1 (K) & $\mathbf{4 . 5 3}$ & $\mathbf{4 . 6 1}$ & $\mathbf{4 . 9 7}$ \\
\hline T Outside Condenser 1 TSD2 (K) & 5.04 & 5.02 & 5.35 \\
\hline T Outside Condenser 2 TSD3 (K) & 4.78 & 4.89 & 5.29 \\
\hline T Outside Condenser 3 TSD4 (K) & 5.24 & 5.49 & 5.82 \\
\hline T inside Cryostat Bottom M1 End TRX1 (K) & $\mathbf{4 . 2 5 0}$ & $\mathbf{4 . 2 0 8}$ & $\mathbf{4 . 2 1 6}$ \\
\hline T inside Cryostat Top E2 End TRX2 (K) & $\mathbf{4 . 3 7 2}$ & $\mathbf{4 . 6 6 3}$ & $\mathbf{5 . 1 4 3}$ \\
\hline Liquid Level Lower Gauge (\%) & 99 & 99 & 99 \\
\hline Liquid Level Upper Gauge (\%) & $\sim 12.2$ & $\sim 6.9$ & $<0$ \\
\hline
\end{tabular}

At all currents shown in Table 1, the temperature in the gas space at the top of the E2 end of the magnet cryostat is higher than the liquid temperature at the bottom of the magnet cryostat at the M1 end of the magnet. When the magnet cryostat is filled with liquid helium TRX1 is higher than TRX2, because the pressure at the bottom of the cryostat is higher than the pressure at the top of the cryostat. (On the saturated liquid line, a higher pressure corresponds to a higher temperature.) As the current increased, the temperature in the gas space increased. One guess as to why the temperature increased is AC loss heating that is transferred to the gas in the cryostat as the magnet is charged.

When the temperature rise from sensor TRX2 was first observed, it was thought that the temperature sensor might be faulty. What convinced us that the sensor was not faulty was the temperatures measured on the outside of the cryostat near TRX 2 using silicon diode sensor TSD1. The temperature measured by TSD1 went up, even though the apparent temperature measured by the diode should go down because of the magnetic field generated by the current in the magnet. There were similar temperature increases 
shown by sensors TSD2 through TSD4, which are located on the outside of the cooler stainless steel tubes near the stage- 2 condensers for all three coolers.

Figure 3 shows the conductor load lines for a single conductor at three radii outside of the spectrometer solenoid center coil at $275 \mathrm{~A}$. At the peak field point inside the coil near the $\mathrm{E} 2$ end $\left(\mathrm{B}_{\mathrm{p}}=\sim 4.6 \mathrm{~T}\right)$, the critical temperature of the conductor is about $6.4 \mathrm{~K}$.

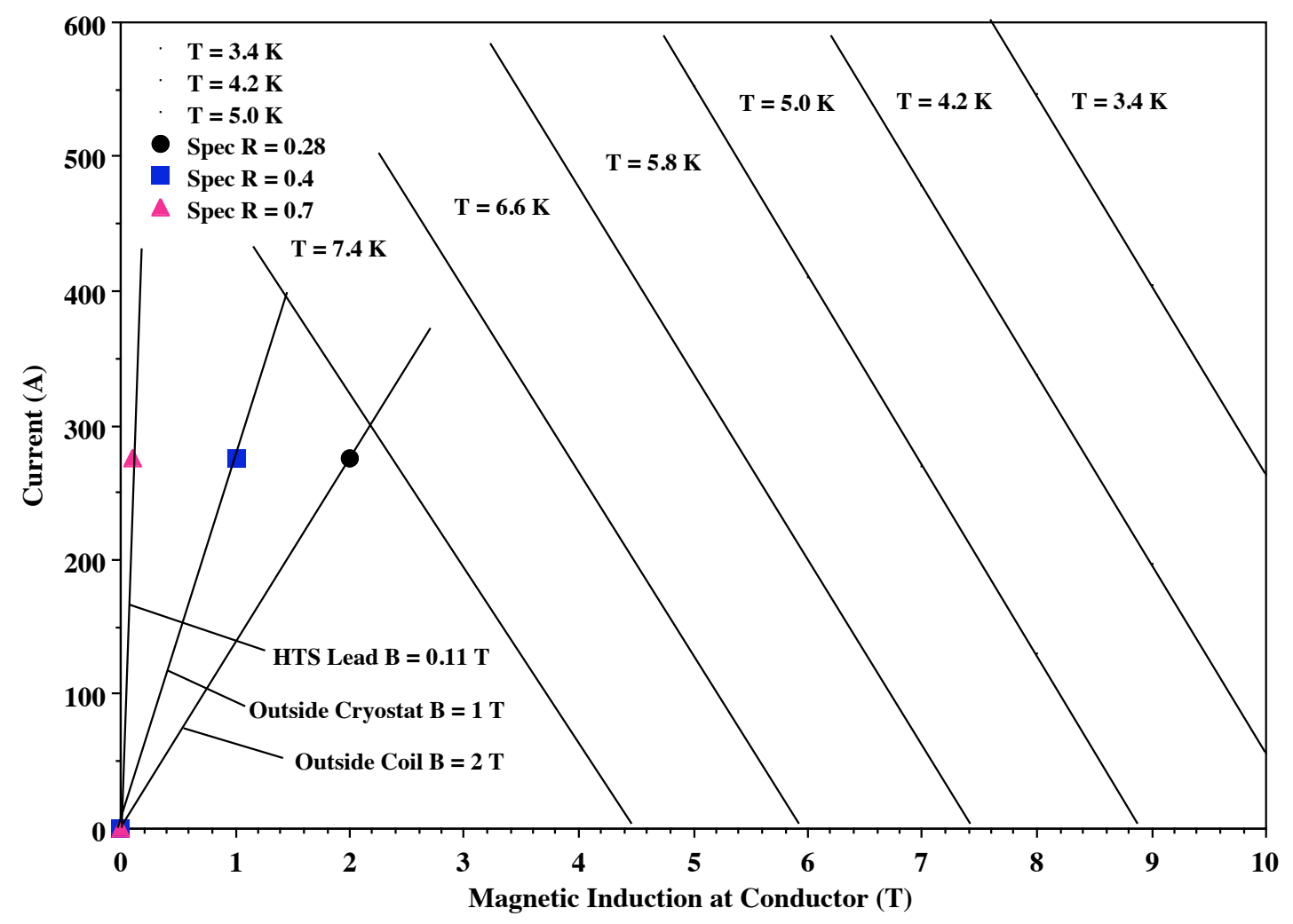

Figure 3. Conductor load lines for a single superconducting lead located outside of the center coil of the MICE spectrometer solenoid.

Figure 3 shows that the critical temperature of the niobium-titanium conductor is greater than $7.4 \mathrm{~K}$, even when the induction outside of the center coil is about $1 \mathrm{~T}$. The region at $0.5 \mathrm{~T}$ is just outside of the cold mass where the vacuum tight feed-through passes through the shell. The region that is at $0.2 \mathrm{~T}$ is at the low temperature end of the HTS leads for the spectrometer solenoid. At the top of the leads the induction is $<0.1 \mathrm{~T}$. It is clear that temperature alone is very unlikely to be the cause of the failure of the M2 coil lead. It is likely that some other factor led to the break of the lead of coil M2.

Rapid conductor motion in a magnetic field can cause AC losses in the conductor. If the conductor is poorly cooled, it is possible that the conductor temperature could become higher than its critical temperature. Conductor motion can be caused by magnetic forces. In much of the region in and around the diodes, the direction of the current in the conductor is the same as the magnetic field direction. These conductors are also well supported. In the region on the helium side of the feed-through, there is the potential for conductor motion due to the magnetic field, because some flexibility was built into the system to enable the magnet leads to be connected to the feed-through. 
Since the region between the outer surface of the center coil and the outside of the feed-through is at a magnetic induction of 0.5 to $1 \mathrm{~T}$, there is the ability to generate $\mathrm{I} \times \mathrm{B}$ forces as high as $275 \mathrm{~N} / \mathrm{m}$ in the wire. The unsupported length of wire is supposed to be short, but there is the possibility that such forces could generate enough conductor motion to result in a wire quench.

Because the magnet cold mass moves with respect to the bottom of the HTS during the magnet cool-down, there must be some flexibility between the bottom of the HTS leads and the top of the structure that carries the magnet leads between the vacuum side of the feed-through and the HTS leads. The field in this region is much lower than it is around the feed-through that goes into the magnet helium tank. Since the magnetic field is lower $(\sim 0.15$ to $0.2 \mathrm{~T})$, the forces are much lower $(<50 \mathrm{~N} / \mathrm{m})$ in this region. If the failure occurred in this region, it seems unlikely that the elevated temperature of the gas in the upper part of the cryostat had anything to do with the lead failure.

It is unlikely that a quench of the magnet (with all coils connected in series) caused the lead to coil M2 to fail. When the magnet quenches, the current decays to zero in roughly $5 \mathrm{~s}$. If the M2 coil lead went normal due to the magnet quench, its current would also decay is about $5 \mathrm{~s}$. Even at the full design current for the spectrometer magnet, the heating in the lead would not be any hotter than the adiabatic hot spot temperature for the whole coil, which is $<300 \mathrm{~K}$.

In general, it is implausible that the heating at the top of the helium vessel was the cause of the M2 lead failure. The increased temperature in the top of the gas space around coil E2 is a symptom of AC losses in the conductor due to coil charging and poor cooling. AC losses due to conductor motion generated by magnetic field forces appear to be a potential cause of the conductor failure for the M2 coil. The heating of the gas at the top of the cryostat reduces the temperature margin for any conductor that might move due to magnetic forces. If the failure of the M2 lead occurred inside of the cold mass helium vessel, poor cooling of the conductor in helium gas could be a contributing factor to the lead failure.

\section{Magnet Calorimetric Measurements of the Net Heat Flow at $4 \mathrm{~K}$}

Calorimetric measurements were done late in the test. The spectrometer magnet $2 \mathrm{~B}$ has three two-stage Cryomech PT415 pulse tube coolers that can generate $1.5 \mathrm{~W}$ each at $4.2 \mathrm{~K}$, when the cooler first stage heat load is about $45 \mathrm{~W}$. In addition, there is a single stage Cryomech AL-330 GM cooler that can generate $170 \mathrm{~W}$ at $50 \mathrm{~K}$ on $60 \mathrm{~Hz}$ power.

On March 29, the silicon diode temperature sensors on the cooler second stages were connected. We managed to get some data on the temperature of the cooler second stages using these sensors. For example, at 16:05 on March 29, the following temperatures were read by the second-stage sensors: The second-stage of cooler 1 sensor TSD5 varied from 4.315 to $4.479 \mathrm{~K}$. The second-stage of cooler 2 sensor TSD6 varied from 4.678 to $4.914 \mathrm{~K}$. The second-stage of cooler 3 sensor TSD7 varied from 4.766 to $5.204 \mathrm{~K}$. At this time, the temperature measured by Cernox sensor TRX1 (bottom of the He tank at the M1 end) was $4.407 \mathrm{~K}$ and Cernox sensor TRX2 (top of the He tank at the E2 end) was $4.405 \mathrm{~K}$. The diode sensors read temperature variations due to the pulsing of the gas in the second stage pulse tube and regenerator tube. Since the specific heat of the second stage is low, the temperature variation is seen by the sensors. The diodes were not calibrated, so the best that can be said is that the temperatures were in the correct range. 
At no time during the calorimetric tests, did the coolers hold the magnet thermal load at $4 \mathrm{~K}$. In all cases, there was a net boil-off of liquid helium. Three methods were used to determine the excess heat load at $4 \mathrm{~K}$. They were; 1) measurement of the liquid level drop in the tank, 2) measurement of the tank helium temperature with the tank valved-off, and 3) a direct measurement of the helium boil off using a gas meter.

The first method for determining the magnet helium boil-off was to measure the liquid level drop within the tank. The best measurements were taken from 12:26 PM on 27 March 2010 to 8:50 AM on 29 March 2010. The liquid level dropped from 99.0 percent on the upper level gauge to 0.1 percent on the upper level gauge. All of the time, the lower level gauge was fully covered. At best, this level drop represented $\sim 75$ liters. At worst the level drop was 105 liters. The uncertainty comes because the upper level gauge sometimes reads a small amount when there is no liquid touching it. The pressure in the tank during this time was 2 psig (1.148 bar). At this pressure, the liquid helium density is $122.1 \mathrm{~g} / \mathrm{L}$. The heat of vaporization at this pressure is $19.87 \mathrm{~J} \mathrm{~g}^{-1}$. The average boil-off rate during those 44.4 hours was from $1.69 \mathrm{~L} / \mathrm{hr}$ to $2.36 \mathrm{~L} / \mathrm{hr}$. At a tank pressure of 1.148 bar, the boil-off rate varied from $0.057 \mathrm{~g} \mathrm{~s}^{-1}$ to $0.081 \mathrm{~g} \mathrm{~s}^{-1}$. The excess heat load needed to generate the measured boil-off varied from $1.13 \mathrm{~W}$ to $1.61 \mathrm{~W}$. Using the drop in the liquid level in the helium tank as a measure of helium boil-off has a lot of uncertainty. The measurement quoted above may be the best measurement that one can get from liquid level measurements, because it represents about half of the tank volume. The liquid level gauges only measure 75 percent of the tank volume, and the liquid level gauges are non-linear. Depending on how the calculation of the tank volume is done, one comes up with a total tank volume between 180 liters and 195 liters. The average tank temperature was about $4.36 \mathrm{~K}$.

The second method employed to measure the excess heat leak into the solenoid involved filling the tank into the manifold volume. The tank pressure at this time was about $0.3 \mathrm{psig}$ (1.031 bar). At this pressure, the nominal temperature of the helium in the tank should be $4.242 \mathrm{~K}$ (assuming that Wang NMR is a sea level and the weather is clear). The measured Cernox temperature data were $4.193 \mathrm{~K}$ on TRX1 and $4.191 \mathrm{~K}$ on TRX2. The helium tank was valved off and the pressure was allowed to rise. Over a tenminute period, the average temperature of the helium in the tank increased from $4.192 \mathrm{~K}$ to $4.203 \mathrm{~K}$ (using Cernox sensors TRX1 and TRX2). During this time, the three-coil set $(\mathrm{E} 1+\mathrm{C}+\mathrm{E} 2)$ in the magnet was being charged at the rate of $0.06 \mathrm{~A} \mathrm{~s}^{-1}$ from a current of about 60 A to $96 \mathrm{~A}$. Since the magnet helium tank is full, the helium mass is dominated by the liquid mass. The liquid mass in the tank was from $22.4 \mathrm{~kg}$ to $23.9 \mathrm{~kg}$ (at $4.25 \mathrm{~K}$ ) depending on the actual volume of the tank. The mass of the gas in the helium tank is estimated to be from $0.035 \mathrm{~kg}$ to $0.06 \mathrm{~kg}$ depending on the actual gas volume in the tank. At constant specific volume, the liquid helium specific heat is $2557 \mathrm{~J} \mathrm{~kg}^{-1} \mathrm{~T}^{-1}$. At constant specific volume the specific heat of the gas is $3232 \mathrm{~J} \mathrm{~kg}^{-1} \mathrm{~T}^{-1}$. For a temperature rise of $0.011 \mathrm{~K}$ at constant volume, the liquid had from 630 to $672 \mathrm{~J}$ of heat added. For a temperature increase of $0.011 \mathrm{~K}$ at constant volume, the gas had from $1.2 \mathrm{~J}$ to $2.2 \mathrm{~J}$ added. The $0.011 \mathrm{~K}$ temperature change occurred over a time of about 10 minutes $(600 \mathrm{~s}$ $\pm 30 \mathrm{~s})$. This indicates that the excess $4 \mathrm{~K}$ heat load was from $1.05 \mathrm{~W}$ to $1.24 \mathrm{~W}$. Before the helium tank vent valve was closed to measure the temperature rise, the helium boiloff rate appeared to be very low. We didn't have a gas meter to measure the boil off, so the observation must be considered to be anecdotal. 
The third method of measuring the excess heat flow into magnet $2 \mathrm{~B}$ involved measuring the boil-off of helium from the tank while it was kept at constant pressure. This test was done with the helium tank about 25 percent full and at a tank pressure that ranged from 3.7 to $4.1 \mathrm{psig}$ (from 1.265 to $1.292 \mathrm{bar}$ ). The nominal helium temperature was 4.46 to $4.48 \mathrm{~K}$ (based on the tank pressure). The temperature measured by the Cernox sensor TRX1 was from 4.501 to $4.542 \mathrm{~K}$. The higher tank pressure and higher helium temperature correspond to charging the three-coil set from 0 to $100 \mathrm{~A}$ at the rate of $0.05 \mathrm{~A} / \mathrm{s}$. Once the three-coil set was powered to $100 \mathrm{~A}$, the tank pressure went down to $3.9 \mathrm{psig}$ and the tank temperature went down to $4.524 \mathrm{~K}$ on TRX1. The temperature measured by TRX2 (the gas on top of coil E2) was about $0.08 \mathrm{~K}$ higher than the temperature measured by TRX1 (the liquid at the bottom of coil M1.) This temperature difference was the same with and without current in the three-coil set.

At standard temperature and pressure $(273.15 \mathrm{~K}$ at $1.013 \mathrm{bar}), 1$ mole of helium occupies 22.4 liters. The temperature the day we did the gas flow measurement was $16 \mathrm{C}$ $(289.15 \mathrm{~K})$. One cubic foot is 28.317 liters; so $1 \mathrm{ft}^{3}$ at $289.16 \mathrm{~K}$ contains 4.78 grams of helium gas. The gas meter used was a standard positive displacement gas meter commonly used for natural gas. The meter had a hand that rotated at the rate of one revolution per cubic foot. One simply had to measure the time that it took for this hand to make one revolution. During a period of time from 10:42 AM on 31 March 2010 to 4:00 PM on the same date a number of measurements of the gas flow were made. The time for one cubic foot of helium at $16 \mathrm{C}$ to go through the meter ranged from 59 seconds to 65 seconds. The shortest time for one cubic foot of helium to pass through the meter occurred as the magnet three coil set was being charged from 0 to $100 \mathrm{~A}$ at the rate of $0.05 \mathrm{~A} \mathrm{~s}^{-1}$. Once the magnet was charged to $100 \mathrm{~A}$, the magnet current stayed at $100 \mathrm{~A}$ for 2 hours and 24 minutes. At the end of that time, the time for one cubic foot of helium to go through the meter was 63 seconds. Once the magnet was discharged, the time for one cubic foot of helium to go through the meter increased to 64 seconds. During the measurement of the gas flow through the meter the range of boil-off rates was $0.074 \mathrm{~g} \mathrm{~s}^{-1}$ $\left(1 \mathrm{ft}^{3}\right.$ in $\left.65 \mathrm{~s}\right)$ to $0.081 \mathrm{~g} \mathrm{~s}^{-1}\left(1 \mathrm{ft}^{3}\right.$ in $\left.59 \mathrm{~s}\right)$. At a temperature of $4.47 \mathrm{~K}$ (a cryostat pressure of 1.278 bar), the heat of vaporization of helium is $19.03 \mathrm{~J} \mathrm{~g}^{-1}$. The liquid level on the lower gauge dropped from $54.4 \%$ to $33.3 \%$. During this period of time (5.30 hours), $1.584 \mathrm{~kg}$ (13.2 liquid liters) of helium was boiled away. The excess heat load with the helium tank a little less than one quarter full ranged from $1.40 \mathrm{~W}$ to $1.55 \mathrm{~W}$.

Table 2. The excess heat load measured by various methods (ordered by liquid level).

\begin{tabular}{|c|c|c|c|c|}
\hline Method & $\begin{array}{c}\text { LHe } \\
\text { Volume* }\end{array}$ & Tank P & He Temp & Excess Heat Load Range \\
\hline Gas Meter & $\sim 40 \mathrm{~L}$ & $1.278 \mathrm{bar}$ & $4.542 \mathrm{~K}$ & $\mathbf{1 . 4 0} \mathbf{W}$ to $1.55 \mathrm{~W}$ \\
\hline Liquid Level & $\sim 135 \mathrm{~L}$ & $1.148 \mathrm{bar}$ & $\sim 4.36 \mathrm{~K}$ & $\mathbf{1 . 1 6} \mathbf{W}$ to $1.61 \mathbf{W}^{* *}$ \\
\hline Constant V & $\sim 185 \mathrm{~L}$ & $1.031 \mathrm{bar}$ & $4.242 \mathrm{~K}$ & $\mathbf{1 . 0 5} \mathbf{W}$ to $1.24 \mathbf{W}$ \\
\hline
\end{tabular}

* This value is based on a helium tank volume of 185 liters.

** This method has a lot of uncertainty because the helium level may be below the level gauge. 
Table 2 summarizes the measurements of the excess heat load into the magnet cold mass. The measurements using the liquid-level change have the greatest uncertainty. Measurements done at constant volume also have some uncertainty because the tank volume is not precisely known. The range in the constant volume measurements reflects the uncertainty in the tank volume. The measurements using the gas meter are the most accurate measurements. From Table 2, it appears that the excess heat load is higher when the liquid level is lower. This appears to be true despite the fact that the coolers can provide more cooling at higher temperatures. The data shown in Table 2 suggest that the liquid level in the helium tank should be kept high. A high liquid level means that the temperature at the top of the tank will be colder. Colder gas re-condenses more readily.

Table 2 suggests that the heat load into the cold mass can almost be removed by four two-stage coolers. To have some margin, five two-stage coolers may be a more reasonable choice, especially considering that our measurements were all made with no contribution from $I^{2} R$ heating in the leads. The excess heat measured may be a manifestation of a poor connection between the cooler second-stage and the magnet helium tank, but it nonetheless represents the additional cooling that must be provided. Evidence of this is that the excess heat appears to increase when the liquid level is lower. It is important to remove extraneous sources of heat into the magnet mass. It is equally important to improve the connection between the cooler condensers and the magnet helium tank, if possible.

\section{Resistive Heating in the HTS Leads, Is this real?}

The cooler and lead tests [11] results suggest that there may be resistive heating in the HTS leads. The literature from HTS-110, the vendor for the leads does not mention that there is resistive heating in the HTS leads. Unfortunately this data was only taken for one set of HTS leads, which was contrary to the written test plan. Table 3 shows the measured resistive heating for the leads used in Magnet 2 as a function of lead current. Table 4 shows the resistive heating for leads used in Magnet 2 carrying $275 \mathrm{~A}$ as a function of the added heat on the copper plate.

Table 3. Measured resistive heating in various parts of the current circuit used in the cooler and lead test using the magnet $2 \mathrm{~B}$ copper leads.

\begin{tabular}{|c|c|c|c|c|c|c|c|c|}
\hline \multirow{2}{*}{ Tap } & \multicolumn{7}{|c|}{ Resistive Heating (mW) } & \multirow[b]{3}{*}{ Cu Lead \#2 } \\
\hline & $275 \mathrm{~A}$ & $250 \mathrm{~A}$ & $200 \mathrm{~A}$ & $150 \mathrm{~A}$ & $100 \mathrm{~A}$ & $50 \mathrm{~A}$ & $10 \mathrm{~A}$ & \\
\hline V1-3 & 11234.6 & 10052.1 & 7402.0 & 5286.9 & 3269.0 & 1506.8 & 281.5 & \\
\hline V4-2 & 10948.1 & 9617.6 & 7300.5 & 5038.2 & 3140.3 & 1465.4 & 278.1 & \multirow{8}{*}{$\begin{array}{l}\text { Cu Lead \#1 } \\
\text { HTS Lead \#2 } \\
\text { HTS Lead \#1 }\end{array}$} \\
\hline V3-5 & 56.35 & 49.89 & 36.49 & 26.46 & 16.99 & 8.25 & 1.93 & \\
\hline V6-4 & 44.63 & 37.21 & 27.56 & 18.21 & 10.73 & 4.54 & 0.55 & \\
\hline V5-7 & 2.61 & 1.76 & 0.88 & 0.30 & 0.33 & 0.08 & 0.06 & \\
\hline V7-9 & 0.96 & 0.94 & 0.83 & 0.88 & 0.66 & 0.69 & 0.63 & \\
\hline V9-10 & 1.21 & 1.35 & 0.72 & 0.25 & 0.39 & 0.06 & 0.11 & \\
\hline V8-6 & 4.29 & 3.36 & 1.79 & 0.91 & 0.44 & 0.22 & 0.03 & \\
\hline V10-8 & 2.86 & 1.57 & 1.32 & 0.85 & 0.69 & 0.77 & 0.14 & \\
\hline & 11.94 & 8.97 & 5.53 & 3.19 & 2.50 & 1.82 & 0.96 & \multirow{2}{*}{$\begin{array}{l}\text { Total Other } \\
\text { Total IR Hea }\end{array}$} \\
\hline & 22295.7 & 19765.8 & 14772.1 & 10372.9 & 6439.5 & 2986.8 & 563.0 & \\
\hline
\end{tabular}


Table 4. Measured resistive heating in various parts of the current circuit used in the cooler and lead test with $275 \mathrm{~A}$ in the magnet 2B copper leads with added heat on the copper plate.

\begin{tabular}{|c|c|c|c|c|c|c|}
\hline & \multicolumn{5}{|c|}{ Resistive Heating (mW) } & \multirow{14}{*}{$\begin{array}{l}\text { Cu Lead \#2 } \\
\text { Cu Lead \#1 } \\
\text { HTS Lead \#2 } \\
\text { HTS Lead \#1 }\end{array}$} \\
\hline Time & 3:30 PM & 5:00 PM & 5:30 PM & 6:00 PM & $6: 45 \mathrm{PM}$ & \\
\hline Added Q (W) & $0 \mathrm{~W}$ & $30 \mathrm{~W}$ & $30 \mathrm{~W}$ & $0 \mathrm{~W}$ & $0 \mathrm{~W}$ & \\
\hline V1-3 & 10171.3 & 11752.5 & 11842.6 & 11621.3 & 11234.7 & \\
\hline V4-2 & 9869.1 & 11473.4 & 11547.2 & 11278.1 & 10948.1 & \\
\hline $\mathrm{V} 3-5$ & 37.62 & 78.84 & 82.36 & 69.80 & 56.35 & \\
\hline V6-4 & 34.76 & 56.13 & 57.34 & 50.08 & 44.63 & \\
\hline V5-7 & 1.21 & 1.95 & 2.75 & 2.75 & 2.61 & \\
\hline V7-9 & 9.02 & 7.81 & 9.93 & 4.02 & 0.96 & \\
\hline V9-10 & 1.04 & 1.18 & 0.88 & 1.16 & 1.21 & \\
\hline V8-6 & 3.27 & 5.50 & 4.95 & 4.95 & 4.29 & \\
\hline \multirow[t]{3}{*}{ V10-8 } & 7.10 & 10.26 & 10.89 & 5.17 & 2.86 & \\
\hline & 21.64 & 26.70 & 29.40 & 18.04 & 11.94 & \\
\hline & 20134.5 & 23387.5 & 23558.9 & 23037.2 & 22295.7 & \\
\hline
\end{tabular}

From Table 3, it appears that $101 \mathrm{~mW}$ is generated in the HTS leads when they carry a current of $275 \mathrm{~A}$. When the leads carry $150 \mathrm{~A}$, the apparent resistive heating in the HTS leads is $44.7 \mathrm{~mW}$. This relationship suggests that the heating is proportional to the lead current squared. When on looks at Table 4, it appears that the apparent resistive heating is a function of the heat generated by the copper leads that are connected to the HTS leads. When heat is applied to the copper plate, it temperature goes up. The resistance of the copper leads and lead intercepts attached to the copper plate goes up because the copper resistivity is increased. The apparent resistive heating in the HTS leads may be from the copper. The magnitude of this effect may be a function of where the voltage taps are located at the top of the copper plate. Further investigation is needed to determine whether the apparent restive heating in the HTS leads is real.

\section{Measured Cooler First-stage Heat Loads with No Current in the Magnet}

On 29 March 2010, the temperature sensors for the four coolers were connected to the display. The sensor designations are as follows: Cooler 1 first-stage TPR14, secondstage TSD5; Cooler 2 first stage TPR15, second stage TSD6; Cooler 3 first stage TPR16, second stage TSD7; and the AL330 single-stage cooler TPR13. Using the sensors on the copper plate TPR4 (near cooler 1), TPR5 (near cooler 2), TPR6 (near cooler 3), and TPR3 (the copper plate at the opposite end of the lead string) on can determine the temperature differences within the system. From this data and the data we have from the lead test, we can estimate the heat into the cooler first stage for all four coolers. 


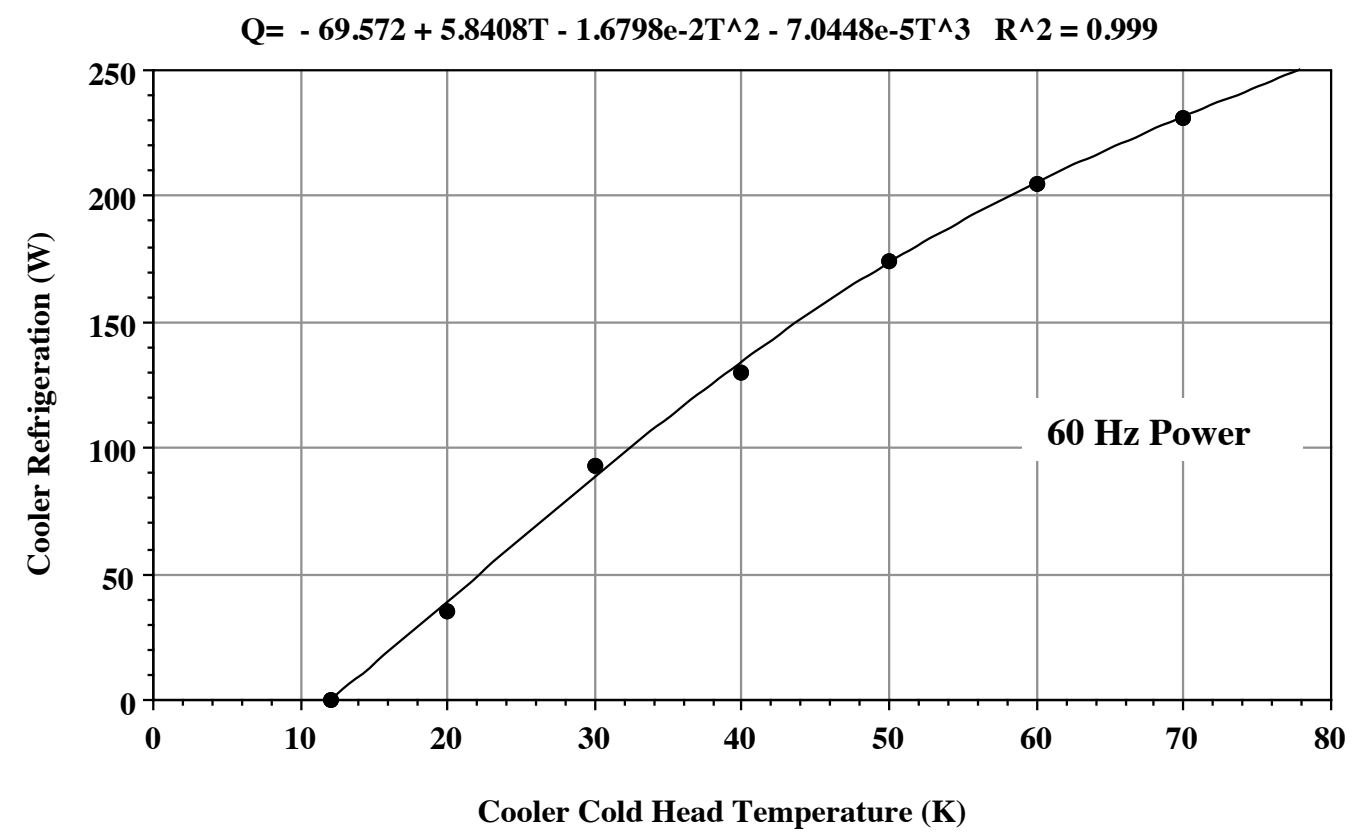

Figure 4. AL-330 cooler refrigeration as a function of the cold -head temperature.

Figure 4 presents the cooler refrigeration capacity of an AL-330 single stage cooler as a function of the cold-head temperature [12]. The curve fit is based on points taken from a curve provided by Cryomech. The expression above applies when the compressor and cold head operate at $60 \mathrm{~Hz}$. When the line frequency is $50 \mathrm{~Hz}$, the refrigeration output might be as low as $83 \%$ of the value given by the equation above.

From Figure 1, one can determine the first-stage refrigeration produced by a PT415 cooler as a function of the cooler first-stage temperature T1 and the second-stage temperature T2. When one looks at Figure 1 with about $1.5 \mathrm{~W}$ being produced on the second stage of the cooler, one sees that between $41 \mathrm{~K}$ on the first stage to $52 \mathrm{~K}$ on the first stage, the cooling is nearly linear with the first stage temperature. The following expression can be used to estimate the first stage cooling Q1 as a function of the firststage temperature, $\mathrm{T} 1$ :

$$
Q 1=40+1.92(T 1-40)
$$

It is reasonable to use Equation 1 over a first stage temperature range from 40 to $55 \mathrm{~K}$ and a range of second stage heat loads from $0.8 \mathrm{~W}$ to about $1.8 \mathrm{~W}$. Outside this range, one should use Figure 1 to determine the first-stage refrigeration. The Cryomech PT415 cooler produces the same cooling running at $50 \mathrm{~Hz}$ as it does at $60 \mathrm{~Hz}$, provided the cooler is charged to the correct pressure for $50 \mathrm{~Hz}$ operation.

Table 5 shows the heat removed by the first stages of the three PT415 two-stage coolers and the single stage AL-330 cooler. The cooling estimate shown in the sixth column in Table 5 was estimated using equation 1 for the PT-415 coolers. For the AL330 single-stage cooler, the estimated refrigeration came from Figure 4. 
Table 5. Cooler first-stage temperature, $\mathrm{Cu}$ plate temperature, $\Delta \mathrm{T}$ between the $\mathrm{Cu}$ plate and cooler first stage, and the heat flow into the cooler first stages on 29 March 2010.

\begin{tabular}{|c|c|c|c|c|c|}
\hline Date and Time & Cooler & $\begin{array}{c}\mathbf{1}^{\text {st }} \text { Stage T } \\
(\mathrm{K})\end{array}$ & $\begin{array}{c}\text { Cu Plate T } \\
(\mathbf{K})\end{array}$ & $\Delta \mathbf{T}(\mathrm{K})$ & $\begin{array}{c}\text { Cooling } \\
\text { (W) }\end{array}$ \\
\hline \multirow{5}{*}{$\begin{array}{c}29 \text { March } 10 \\
16: 05\end{array}$} & Cooler 1 & 44.00 & 49.50 & 5.50 & $\sim 48$ \\
\hline & Cooler 2 & 43.22 & No data & $4.89 *$ & $\sim 46$ \\
\hline & Cooler 3 & 42.70 & 46.98 & 4.28 & $\sim 45$ \\
\hline & AL-330 & 42.00 & 43.79 & 1.79 & $\sim 138$ \\
\hline & \multicolumn{4}{|c|}{ Total First-stage Heat Load } & $\sim 277$ \\
\hline \multirow{5}{*}{$\begin{array}{c}29 \text { March } 10 \\
18: 10\end{array}$} & Cooler 1 & 43.96 & 49.43 & 5.47 & $\sim 48$ \\
\hline & Cooler 2 & 43.27 & No data & $4.93 *$ & $\sim 46$ \\
\hline & Cooler 3 & 42.50 & 46.89 & 4.39 & $\sim 45$ \\
\hline & AL-330 & 41.95 & 43.72 & 1.77 & $\sim 138$ \\
\hline & \multicolumn{4}{|c|}{ Total First-stage Heat Load } & $\sim 277$ \\
\hline
\end{tabular}

* This estimate is based on an average of $\Delta \mathrm{T}$ for coolers 1 and 3.

In the test of magnet $2 \mathrm{~B}$, the single-stage cooler removed about $60 \mathrm{~W}$ that came down the copper leads from $300 \mathrm{~K}$ (with no current flowing in the copper leads) plus an additional $78 \mathrm{~W}$ from the shield. Coolers 1 through 3 removed about $139 \mathrm{~W}$ from the shield. The total heat flow into the shield from all sources is very close to the same as was calculated for magnet 2 when it was last tested in July 2009. The total heat load shown in Table 5 is from 100 to $105 \mathrm{~W}$ higher than the estimated heat load to the shield from all sources in magnet 1 when it was tested in the summer of 2008. The reason for this difference is presently not understood.

\section{Estimated Cooler First-stage Heat Loads with Current in the Magnet}

Because we ran cooler and lead tests and we have measurements of cooler first-stage temperatures without current in the leads, we can estimate the heat loads to the first stages of all of the magnet coolers when the magnet is powered in series with the six leads that are designed to carry currents of $275 \mathrm{~A}$. Two assumptions were made to estimate the first-stage heat loads: 1 ) the $\Delta \mathrm{T}$ between the copper plate and the cold head is proportional to the heat going into the cold head; and 2) the temperature of the copper plate near cooler 2 is the average of the temperature of the copper plate nears coolers 1 and 3. The measured data from the first section of Table 5 was used for the zero current case and the measured data from Table 1 was used for the three current cases where the currents were $140 \mathrm{~A}, 212 \mathrm{~A}$, and $250 \mathrm{~A}$.

One can estimate the heat load into the cooler first stages given the temperature of the copper plate at the four locations that are close to the coolers. The following simplified equation was used to estimate the first stage refrigeration Q1 given the copper plate temperature $\mathrm{T}_{\mathrm{c}}$ in the four places near the coolers;

$$
Q 1=\frac{T c+B C-D}{A+B}
$$

Equation 2 is valid over the same temperature range as Equation 1 for the PT415 coolers. For the AL-330 cooler, Equation 2 is valid for $\mathrm{T} 1=30 \mathrm{~K}$ to $\mathrm{T} 1=55 \mathrm{~K}$. Table 6 gives the numerical values of $\mathrm{A}, \mathrm{B}, \mathrm{C}$, and $\mathrm{D}$, for all coolers in magnet $2 \mathrm{~B}$. 
Table 6. The numerical values for A, B, C, D, for the four coolers on magnet 2B.

\begin{tabular}{|c|c|c|c|c|c|c|}
\hline Cooler & $\begin{array}{c}\mathbf{A} \\
(\mathbf{K} / \mathbf{W})\end{array}$ & $\begin{array}{c}\mathbf{B} \\
(\mathbf{K} / \mathbf{W})\end{array}$ & $\begin{array}{c}\mathbf{C} \\
(\mathbf{W})\end{array}$ & $\begin{array}{c}\mathbf{D} \\
(\mathbf{K})\end{array}$ & $\begin{array}{c}\mathbf{B C}-\mathbf{D} \\
(\mathbf{K})\end{array}$ & $\begin{array}{c}\mathbf{A + B} \\
(\mathbf{K} / \mathbf{W})\end{array}$ \\
\hline 1 & 0.114 & 0.521 & 40 & 40 & -19.2 & 0.635 \\
\hline 2 & 0.106 & 0.521 & 40 & 40 & -19.2 & 0.627 \\
\hline 3 & 0.095 & 0.521 & 40 & 40 & -19.2 & 0.616 \\
\hline AL-330 & 0.013 & 0.224 & 85 & 30 & -11.0 & 0.237 \\
\hline
\end{tabular}

Table 7. $\mathrm{Cu}$ plate temperature, estimated $\Delta \mathrm{T}$ between the $\mathrm{Cu}$ plate and cooler first stage, estimated first-stage temperature, and heat flow into the cooler first stages.

\begin{tabular}{|c|c|c|c|c|c|}
\hline Date and Time & Cooler & $\begin{array}{c}\text { Cu Plate T } \\
(\mathbf{K})\end{array}$ & $\Delta \mathrm{T}(\mathrm{K})$ & $\begin{array}{c}1^{\text {st }} \text { Stage T } \\
(\mathbf{K})\end{array}$ & $\begin{array}{c}\text { Cooling } \\
\text { (W) }\end{array}$ \\
\hline \multirow{5}{*}{$\begin{array}{c}29 \text { March } 10 \\
16: 05 \\
\mathrm{I}=0 \mathrm{~A}\end{array}$} & Cooler 1 & 49.50 & 5.50 & 44.00 & $\sim 48$ \\
\hline & Cooler 2 & $\sim 48.1 *$ & $\sim 4.9^{\wedge}$ & 43.22 & $\sim 46$ \\
\hline & Cooler 3 & 46.98 & 4.28 & 42.70 & $\sim 45$ \\
\hline & AL-330 & 43.79 & 1.79 & 42.00 & $\sim 138$ \\
\hline & \multicolumn{4}{|c|}{ Total First-stage Heat Load } & $\sim 277$ \\
\hline \multirow{5}{*}{$\begin{array}{c}19 \text { March } 10 \\
15: 20 \\
\mathrm{I}=\sim 140 \mathrm{~A}\end{array}$} & Cooler 1 & 50.53 & $\sim 5.7$ & $\sim 44.8$ & $\sim 50$ \\
\hline & Cooler 2 & $\sim 49.7 *$ & $\sim 5.2$ & $\sim 44.5$ & $\sim 49$ \\
\hline & Cooler 3 & 48.82 & $\sim 4.6$ & $\sim 44.2$ & $\sim 48$ \\
\hline & AL-330 & 45.45 & $\sim 1.9$ & $\sim 43.5$ & $\sim 145$ \\
\hline & \multicolumn{4}{|c|}{ Total First-stage Heat Load } & $\sim 292$ \\
\hline \multirow{5}{*}{$\begin{array}{c}19 \text { March } 10 \\
16: 12 \\
\mathrm{I}=\sim 212 \mathrm{~A}\end{array}$} & Cooler 1 & 50.49 & $\sim 5.6$ & $\sim 44.9$ & $\sim 49$ \\
\hline & Cooler 2 & $\sim 49.9 *$ & $\sim 5.3$ & $\sim 44.6$ & $\sim 49$ \\
\hline & Cooler 3 & 49.38 & $\sim 4.6$ & $\sim 44.8$ & $\sim 49$ \\
\hline & AL-330 & 46.63 & $\sim 2.0$ & $\sim 44.6$ & $\sim 150$ \\
\hline & \multicolumn{4}{|c|}{ Total First Stage Heat Load } & $\sim 297$ \\
\hline \multirow{5}{*}{$\begin{array}{c}19 \text { March } 10 \\
16: 16 \\
\mathrm{I}=\sim 250 \mathrm{~A}\end{array}$} & Cooler 1 & 50.75 & $\sim 5.7$ & $\sim 45.1$ & $\sim 50$ \\
\hline & Cooler 2 & $\sim 50.6^{*}$ & $\sim 5.3$ & $\sim 45.3$ & $\sim 50$ \\
\hline & Cooler 3 & 50.47 & $\sim 4.8$ & $\sim 45.6$ & $\sim 51$ \\
\hline & A-330 & 48.17 & $\sim 2.0$ & $\sim 46.2$ & $\sim 157$ \\
\hline & \multicolumn{4}{|c|}{ Total First Stage Heat Load } & $\sim 308$ \\
\hline
\end{tabular}

* This estimate is based on an average $\mathrm{T}$ for the $\mathrm{Cu}$ plate for coolers 1 and 3.

$\wedge$ This estimate is based on an average $\Delta \mathrm{T}$ for coolers 1 and 3

The heat flow in the leads due to the current is about three times what was measured in the cooler and lead experiment. The heat flow down a pair of $275 \mathrm{~A}$ leads with no current was $\sim 18 \mathrm{~W}$. With $275 \mathrm{~A}$ in the leads, the heat flow down a pair of $275 \mathrm{~A}$ leads was $\sim 33 \mathrm{~W}$. With all leads carrying their design current, the expected heat flow into the first-stages of the four coolers would be $\sim 322 \mathrm{~W}$. As magnet $2 \mathrm{~B}$ is powered to full current, the heat flow to the first stages will increase about 17 percent. The heat flow into the second stages does not appear to increase more than a few percent. 


\section{A Comparison of Magnet 2B, with Magnet $2 A$ and Magnet $1 A$}

Magnet 1 was tested in the summer of 2008. This magnet is referred as Magnet 1A. It was cooled down and the coils were trained to a current just over $200 \mathrm{~A}$. The coils were powered through three pairs of leads designed to carry $275 \mathrm{~A}$. The three coolers did not keep the magnet cold enough to prevent helium boil-off. The helium boil-off rate was 6 to 8 liters per hour. This meant that the excess heat load (above what the coolers were removing from the magnet) was from $4.3 \mathrm{~W}$ to $5.8 \mathrm{~W}$. During the magnet $1 \mathrm{~A}$ test it was clear that there was little or no heat flow from the magnet to the three coolers. The evidence for this was the low temperatures measured by the temperature sensors on the outside of the can where the second-stage condensers are located. During the magnet 1A test, the magnet shield temperatures were in the range from $92 \mathrm{~K}$ to $107 \mathrm{~K}$, while the copper plate next the three coolers was in the temperature range from $55 \mathrm{~K}$ to $62 \mathrm{~K}$. The copper plate farthest from the coolers was at $61 \mathrm{~K}$. The copper plate temperatures were measured with no current in the leads. There were no temperature sensors on the cold heads of the two-stage coolers at that time. As a result, we could only guess at the amount of heat the three coolers were removing from the system.

Magnet 2 had a number of changes. The way the helium was delivered from the coolers to the magnet was changed to eliminate the "trap" that was in the bottom of magnet one. A nitrogen tank was attached to the shield to pre-cool the shield and the copper plate. There were copper straps attaching the tank to the plate near cooler 2 and near cooler 3. An additional $36.5 \mathrm{~mm}$ ID vent tube was added to reduce the pressure build-up during a quench. Neither vent tube had a good thermal intercept to the shield. The connection between the copper plate and the magnet shield was nominally improved. (Subsequent analysis showed, however, that the heat transfer improvement was essentially nil.)

Magnet 2 was tested the first time during the summer of 2009. During this test, it appeared that the coolers were removing a lot of the heat from the magnet cold mass through the cooler second stages. It appeared that re-condensation was occurring on the second stage cold heads. All of the magnet coils were powered through three pairs of leads designed to carry $275 \mathrm{~A}$. This was the test where the HTS lead burned out because the temperature at the end of the copper plate far from the coolers was too high. This temperature was $\sim 81 \mathrm{~K}$ with no current in the leads and $\sim 93 \mathrm{~K}$ when the HTS lead attached to coil E2 burned-out with $238 \mathrm{~A}$ in the coils. Bert Wang reported at one point that he thought that the cooler was holding the load so that the helium boil-off rate was only 3 liters per day, with no current in the magnet. This would imply that the excess heat leak had to be only about $0.09 \mathrm{~W}$. Subsequent analyses suggest that this measurement of excess heat load was likely in error. During the first test of magnet 2 (now called the magnet $2 \mathrm{~A}$ test), the shield temperature ranged from $107 \mathrm{~K}$ to $116 \mathrm{~K}$. The shield temperatures were from 9 to $15 \mathrm{~K}$ higher than they had been on magnet 1 . The high temperatures on the copper plate and the high temperatures on the shield showed that the heat flow into the cooler first stages was much higher for magnet 2 than for magnet 1. At the time the shield was at these high temperatures, the liquid nitrogen boil-off rate was $\sim 0.75$ liters per hour, which suggests that $32 \mathrm{~W}$ of the shield heat load was being taken up by the boiling nitrogen. As with magnet 1 , there were no temperature sensors on the cold heads of any of the two stage coolers. 
Since high first-stage temperatures, particularly on the lead string, were the problem during the magnet 2A test, a single-stage AL-330 GM cooler was added to the end of the copper plate furthest from the two-stage coolers. The AL-330 cooler can remove $170 \mathrm{~W}$ at $50 \mathrm{~K}$ while operating on $60 \mathrm{~Hz}$ power. The primary purpose of this cooler is to cool the top of the HTS leads and the magnet shield. A secondary purpose of adding this cooler was to put the second-stage cooling into an operating range where the cooling at $4.2 \mathrm{~K}$ can be maximized. All of the changes that were made to magnet 2 were done without removing the magnet cold mass and shield from the main vacuum vessel. Only the turret was opened and modified in order to make the needed changes to the magnet. The way the coolers delivered cooling to the magnet cold mass was not changed from magnet 2A. It should be pointed out that the magnet $2 \mathrm{~B}$ tests were done with no liquid nitrogen in the tank. Based on a thermal analysis of the shield, the temperature of the nitrogen tank should have been about $71 \mathrm{~K}$. At that temperature, there would be no nitrogen boiling.

Table 8 summarizes the measurements made on magnet 1 in 2008, magnet 2 in 2009 and the second test done on magnet 2 in March 2010. The yellow background represents the fact that data were taken without liquid helium in the tank. The turquoise background indicates that the temperature is affected by the new AL-330 cooler.

Table 8. Comparison of magnet temperature data for magnet tests, $1 \mathrm{~A}, 2 \mathrm{~A}$ and $2 \mathrm{~B}$ on various dates from July 2008 to March 2010.

\begin{tabular}{|l|c|c|c|c|}
\hline Magnet Test and Test Date & $\begin{array}{c}\text { 1A } \\
\text { 11 July 08 }\end{array}$ & $\begin{array}{c}\text { 1A } \\
\text { 9 Aug 08 }\end{array}$ & $\begin{array}{c}\text { 2A } \\
\text { 10 July 09 }\end{array}$ & $\begin{array}{c}\text { 2B } \\
\text { 29 Mar 10 }\end{array}$ \\
\hline Cu Plate near Cooler 1 TPR4 (K) & 62.37 & 61.36 & 65.57 & 48.87 \\
\hline Cu Plate near Cooler 2 TPR5 (K) & 55.10 & 55.44 & $\sim 69.9^{\wedge}$ & $\sim 47.6^{\wedge}$ \\
\hline $\mathrm{Cu}$ Plate near Cooler 3 TPR6 (K) & 56.30 & 55.62 & 74.20 & 46.40 \\
\hline Cu Plate far from PT Coolers TPR3 (K) & 60.89 & 60.28 & 80.69 & 43.28 \\
\hline Al Shield under Coolers (K)* & $\sim 80$ & $\sim 81$ & $\sim 95^{* *}$ & $\sim 71$ \\
\hline Shield M1 End Top TPR7 (K) & 92.32 & 93.71 & 106.51 & 84.13 \\
\hline Shield E2 End Bottom TPR8 (K) & 106.95 & 108.81 & 116.01 & 97.31 \\
\hline Cold Mass E2 End Upper TSD1 (K) & 17.96 & 65.20 & 5.169 & 4.987 \\
\hline Outside 2 ${ }^{\text {nd }}$ Stage Cooler 1 TSD2 (K) & 6.41 & 3.37 & 5.392 & 5.115 \\
\hline Outside 2 ${ }^{\text {nd }}$ Stage Cooler 2 TSD3 (K) & 5.61 & 3.51 & 5.042 & 4.858 \\
\hline Outside 2 ${ }^{\text {nd }}$ Stage Cooler 3 TSD4 (K) & 6.13 & 4.03 & 5.537 & 5.314 \\
\hline Inside Tank Lower M1 End TRX1 (K) & No Data & No Data & 4.341 & 4.316 \\
\hline Inside Tank Upper E2 End TRX2 (K) & No Data & No Data & 4.331 & 4.313 \\
\hline Helium Tank Liquid Level (L) & 0 & 0 & $>160$ & $\sim 185$ \\
\hline Helium Tank Pressure (bar) & No Data & No Data & 1.15 & 1.11 \\
\hline LN $_{2}$ Tank Boil-off (L hr $\left.{ }^{-1}\right)$ & No Tank & No Tank & 0.75 & No LN2 \\
\hline
\end{tabular}

$\wedge$ Estimate based on the copper plate temperature at coolers 1 and 3.

* An estimate based on Frederic Trillaud's thermal model of the magnet $6061 \mathrm{Al}$ shield.

** With liquid nitrogen in the tank attached to the shield. 
Table 8 shows a number of factors concerning first-stage heat loads. When one compares the data from the magnet 1 tests with the magnet $2 \mathrm{~A}$ and $2 \mathrm{~B}$ tests, one sees that heat flow into the cooler first-stages was much higher for magnet 2 than it was for magnet 1 . This is clearly demonstrated by the elevated temperature of the copper plate that connects the leads to the three coolers. Magnet 1A has all of the heat from the shield and the leads removed by the first-stages of the three two-stage coolers. Magnet 2A has virtually all of the heat from the copper leads removed by the cooler first-stages. Most of the heat into the shield was also removed by the first-stage of the three two-stage coolers. The portion of the heat load from the shield not removed by the coolers was the portion of the heat that was removed by the boiling liquid nitrogen in the tank. Magnet test 2B is similar to the magnet $1 \mathrm{~A}$ tests in that all of the heat was removed by the coolers.

Table 8 shows some interesting factors concerning the effects of stage-two cooling from the two-stage coolers on the performance of the first stage of the same coolers. When the data for the magnet $1 \mathrm{~A}$ test were taken, we were waiting for the delivery of liquid helium. At that time, liquid helium was difficult to get and the price was over $\$ 10$ per liquid liter. By 2009, the liquid helium was more available and its price was considerably lower. The data given in Table 5 suggest that temperature of the cold mass has little or bearing on the temperature of the shield when the two-stage coolers were running. The cooler first-stage temperature is affected somewhat by the second-stage temperature because heat is pumped to it by the second-stage, but this effect is small.

It appears that in July of 2008, there was some cooling being provided by the cooler second-stages. This may be an explanation for the higher temperatures seen on the copper plate in July 2008. When one looks at the data from August 2008, the copper plate temperatures near the cooler first-stages were lower, even though the cold mass was much warmer. In August 2008, it is clear that there was little or no cooling being provided by the cooler second-stages. The evidence for this is the fact that the temperature on the outside of the stainless steel tube around the condenser was much lower than in August 2008 than in July of 2008 or in July of 2009 when the condenser was at $\sim 4.3 \mathrm{~K}$. The data from August 2008 suggest that the cooler second stage temperatures could have been as low as $3.2 \mathrm{~K}$, which indicates that the cooler second stages were pumping away only the heat conducted down the stainless steel tube between the first stage and the condenser. By August 2008, the cooling system was badly plugged with nitrogen ice, to the extent that the nitrogen ice had migrated into the region around the condensers.

Equation 2 was used to estimate the heat load into the cooler first-stages for magnet tests $1 \mathrm{~A}$ and $2 \mathrm{~A}$, but the values of $\mathrm{A}, \mathrm{B}, \mathrm{C}$, and $\mathrm{D}$ were different. For example, the first stage cold head temperatures $\mathrm{T} 1$ for test $2 \mathrm{~A}$ are likely to be above $55 \mathrm{~K}$ for some of the coolers. As a result, the temperature versus refrigeration curve must be fit over a different temperature range for the PT415 coolers operating with a first stage temperature above $55 \mathrm{~K}$. (The values of A, C and D will be different for these coolers.) In test $1 \mathrm{~A}$, the firststage of cooler 1 had a poor connection to the copper plate. As a result, B is different for this cooler. This cooler did not intercept any of the heat flow from the copper leads, because the copper plate temperature is too high near cooler 1 . The current lead heat load was taken up by coolers 2 and 3. Table 9 shows the values $A+B$ and BC-D used to calculate the heat loads that are given in Table 10 for the Table 8 cases. 
Table 9. Values for A, B, C, D, for the three coolers on magnets 1A, 2A, and 2B.

\begin{tabular}{|c|c|c|c|c|c|c|c|}
\hline Test & Cooler & $\begin{array}{c}\mathbf{A} \\
(\mathbf{K} / \mathbf{W})\end{array}$ & $\begin{array}{c}\mathbf{B} \\
(\mathbf{K} / \mathbf{W})\end{array}$ & $\begin{array}{c}\mathbf{C} \\
(\mathbf{W})\end{array}$ & $\begin{array}{c}\mathbf{D} \\
(\mathbf{K})\end{array}$ & $\begin{array}{c}\mathbf{B C}-\mathbf{D} \\
(\mathbf{K})\end{array}$ & $\begin{array}{c}\mathbf{A + B} \\
(\mathbf{K} / \mathbf{W})\end{array}$ \\
\hline 1A & 1 & 0.521 & $\sim 0.25$ & 40 & 40 & -19.2 & 0.771 \\
\hline 1A & 2 & 0.521 & 0.106 & 40 & 40 & -19.2 & 0.627 \\
\hline 1A & 3 & 0.521 & 0.094 & 40 & 40 & -19.2 & 0.616 \\
\hline 2A & 1 & 0.738 & 0.114 & 63 & 52 & -5.5 & 0.852 \\
\hline 2A & 2 & 0.738 & 0.106 & 63 & 52 & -5.5 & 0.844 \\
\hline 2A & 3 & 0.738 & 0.094 & 63 & 52 & -5.5 & 0.832 \\
\hline 2B & 1 & 0.521 & 0.114 & 40 & 40 & -19.2 & 0.635 \\
\hline 2B & 2 & 0.521 & 0.106 & 40 & 40 & -19.2 & 0.627 \\
\hline 2B & 3 & 0.521 & 0.094 & 40 & 40 & -19.2 & 0.616 \\
\hline 2B & AL-330 & 0.013 & 0.224 & 85 & 30 & -11.0 & 0.235 \\
\hline
\end{tabular}

Table 10. Cu plate temperature, estimated $\Delta \mathrm{T}$ between the $\mathrm{Cu}$ plate and cooler first stage, estimated first-stage temperature, and heat flow into the cooler first stages for tests $1 \mathrm{~A}, 2 \mathrm{~A}$, and $2 \mathrm{~B}$ with no magnet current.

\begin{tabular}{|c|c|c|c|c|c|}
\hline Test and Date & Cooler & $\begin{array}{c}\text { Cu Plate T } \\
(\mathbf{K})\end{array}$ & $\Delta \mathbf{T}(\mathbf{K})$ & $\begin{array}{c}\mathbf{1}^{\text {st }} \text { Stage T } \\
(\mathbf{K})\end{array}$ & $\begin{array}{c}\text { Cooling } \\
\text { (W) }\end{array}$ \\
\hline \multirow{4}{*}{$\begin{array}{c}\text { Test 1A } \\
\text { 11 July } 08\end{array}$} & Cooler 1 & 62.47 & $\sim 14.0$ & $\sim 48.5$ & $\sim 56$ \\
\hline & Cooler 2 & 55.10 & $\sim 6.1$ & $\sim 49.0$ & $\sim 57$ \\
\hline & Cooler 3 & 56.30 & $\sim 5.7$ & $\sim 50.6$ & $\sim 60$ \\
\hline & \multicolumn{4}{|c|}{ Total First-stage Heat Load } & $\sim 173$ \\
\hline \multirow{4}{*}{$\begin{array}{l}\text { Test 1A } \\
9 \text { Aug } 08\end{array}$} & Cooler 1 & 61.36 & $\sim 13.7$ & $\sim 47.7$ & $\sim 55$ \\
\hline & Cooler 2 & 55.44 & $\sim 6.1$ & $\sim 49.3$ & $\sim 58$ \\
\hline & Cooler 3 & 55.62 & $\sim 5.6$ & $\sim 50.0$ & $\sim 59$ \\
\hline & \multicolumn{4}{|c|}{ Total First-stage Heat Load } & $\sim 172$ \\
\hline \multirow{5}{*}{$\begin{array}{c}\text { Test 2A } \\
10 \text { July } 09\end{array}$} & Cooler 1 & 65.67 & $\sim 8.1$ & $\sim 57.6$ & $\sim 71$ \\
\hline & Cooler 2 & $\sim 69.9 *$ & $\sim 8.1$ & $\sim 61.8$ & $\sim 76$ \\
\hline & Cooler 3 & 74.20 & $\sim 7.8$ & $\sim 66.4$ & $\sim 83$ \\
\hline & \multicolumn{4}{|c|}{ Liquid Nitrogen Boil-off } & $\sim 32$ \\
\hline & \multicolumn{4}{|c|}{ Total First Stage Heat Load } & $\sim 262$ \\
\hline \multirow{6}{*}{$\begin{array}{c}\text { Test 2B } \\
29 \text { March } 10\end{array}$} & Cooler 1 & 48.87 & 5.32 & 43.55 & $\sim 47$ \\
\hline & Cooler 2 & $\sim 47.6^{*}$ & $\sim 4.8^{\wedge}$ & $\sim 42.8$ & $\sim 45$ \\
\hline & Cooler 3 & 46.40 & 4.15 & 42.25 & $\sim 44$ \\
\hline & AL-330 & 43.28 & 1.79 & 41.49 & $\sim 138$ \\
\hline & \multicolumn{4}{|c|}{ Liquid Nitrogen Boil-off } & 0 \\
\hline & \multicolumn{4}{|c|}{ Total First Stage Heat Load } & $\sim 274$ \\
\hline
\end{tabular}

* This estimate is based on an average $\mathrm{T}$ for the $\mathrm{Cu}$ plate for coolers 1 and 3.

$\wedge$ This estimate is based on an average $\Delta \mathrm{T}$ for coolers 1 and 3 . 
The difference in the heat leak into the cooler first-stages during magnet test $2 \mathrm{~B}$ as compared to magnet test $2 \mathrm{~A}$ is predominately due to the differences in the heat leak down the leads, with no current in the leads. During the lead and cooler test we measured the leads that were used in magnet $2 \mathrm{~A}$ and the re-designed leads used in magnet $2 \mathrm{~B}$. A pair of the $275 \mathrm{~A}$ leads used in magnet $2 \mathrm{~A}$ had a heat leak of about $10 \mathrm{~W}$ per pair with no current. The same leads operating at full current had a heat leak of about $43 \mathrm{~W}$. A pair of the 275 A leads used in magnet $2 \mathrm{~B}$ had a heat leak of about $18 \mathrm{~W}$ per pair with no current. The same leads operating at full current had a heat leak of about $33 \mathrm{~W}$. When one compares the heat flow into magnet $2 \mathrm{~A}$ and magnet $2 \mathrm{~B}$ without the leads (at zero current), the other heat leaks to the cooler first stages are $\sim 14 \mathrm{~W}$ lower for magnet $2 \mathrm{~B}$. When magnet $2 \mathrm{~A}$ is powered to full current through three pairs of $275 \mathrm{~A}$ leads, the total heat flow into the magnet should be $\sim 360 \mathrm{~W}$. The same operating condition for magnet $2 \mathrm{~B}$ would result in a total heat leak of $\sim 320 \mathrm{~W}$. (This is illustrated by the calculations in Table 4 , which are based on measured data.) In magnets $2 \mathrm{~A}$ and $2 \mathrm{~B}$, the first stage heat loads are much higher than the design called for. The first-stage heat leak for magnet $2 \mathrm{~B}$ is a little better than magnet $2 \mathrm{~A}$, but the difference is small and it could be within the error band. With current in the leads, magnet $2 \mathrm{~B}$ is better than magnet $2 \mathrm{~A}$. It can be argued that this difference is about three times larger than the error band.

Based on the stated helium boil-off rate of $0.125 \mathrm{~L} / \mathrm{hr}(0.09 \mathrm{~W}$ of excess heat leak with no current), it was expected that magnet $2 \mathrm{~B}$ would have a lower heat leak at $4.3 \mathrm{~K}$ than magnet $2 \mathrm{~A}$. The added AL-330 cooler cooled the shield by $\sim 18 \mathrm{~K}$ and the upper end of the HTS leads by $\sim 32 \mathrm{~K}$. This alone will reduce the cold mass heat leak. Because of lower stage-one temperatures, the two-stage coolers can provide more cooling at $4.3 \mathrm{~K}$ in magnet $2 \mathrm{~B}$ than in magnet $2 \mathrm{~A}$ (see Figure 1). Based on the helium boil-off rates measured using a gas meter, we know that the excess heat flow into magnet $2 \mathrm{~B}$ is over ten times what was quoted for magnet $2 \mathrm{~A}$. One is forced to the conclusion that the magnet $2 \mathrm{~A}$ value was in error. We also know that, in magnet $2 \mathrm{~B}$, the heat flow into the first stages of the coolers had little effect on the second-stage cooling (see Figure 1).

The first stage heat leaks into magnet $2 \mathrm{~A}$ are about $90 \mathrm{~W}$ greater than the first-stage heat leaks into magnet 1A. Magnets 1A and 2A have identical leads, so the copper lead design had nothing to do with the difference in the first stage heat load. There were two major changes made in magnet $2 \mathrm{~A}$ as compared to magnet $1 \mathrm{~A}$. First, a liquid nitrogen tank was added to magnet $2 \mathrm{~A}$. Any change in the area of the shield due to the addition of this nitrogen tank should be small (less than 5 percent). The nitrogen tank being attached to the copper plate added another route for the heat to get from the shield to the first stages of coolers 2 and 3 . The total heat leak delivered to the cooler first stages would be the same, except that liquid nitrogen was boiling in the tank removing $32 \mathrm{~W}$, which did not get transferred to the coolers. It is not obvious that the liquid nitrogen tank contributed much added heat leak in magnet $2 \mathrm{~A}$ compared with magnet $1 \mathrm{~A}$. Second, an additional $36.2 \mathrm{~mm}$ ID vent tube was added to magnet 2. This added vent tube does increase the heat leak to the shield and to the cold mass. When one does the calculations, it is hard to come up with more than a few watts of added heat leak into the first stages of the coolers from this source. Thus, neither the nitrogen tank nor added vent tube appear to be significant causes of the added heat leak into the cooler first-stages in magnet 2 . Thus far, we have not identified the "smoking gun." 
Thermal Network Diagrams for Magnet 1A, Magnet 2A and Magnet 2B

The thermal network diagrams presented in this section offer a basis for trying to understand how the three cases behaved when cold. Each case will have a thermal network diagram for the shield part (cooler first-stage) of the magnet and a second diagram for the $4 \mathrm{~K}$ part (cooler second-stage) part of the magnet. For magnet $1 \mathrm{~A}$, see Figs 5 and 6. For magnet 2A, see Figs 7 and 8. For magnet 2B see Figs. 9 and 10.

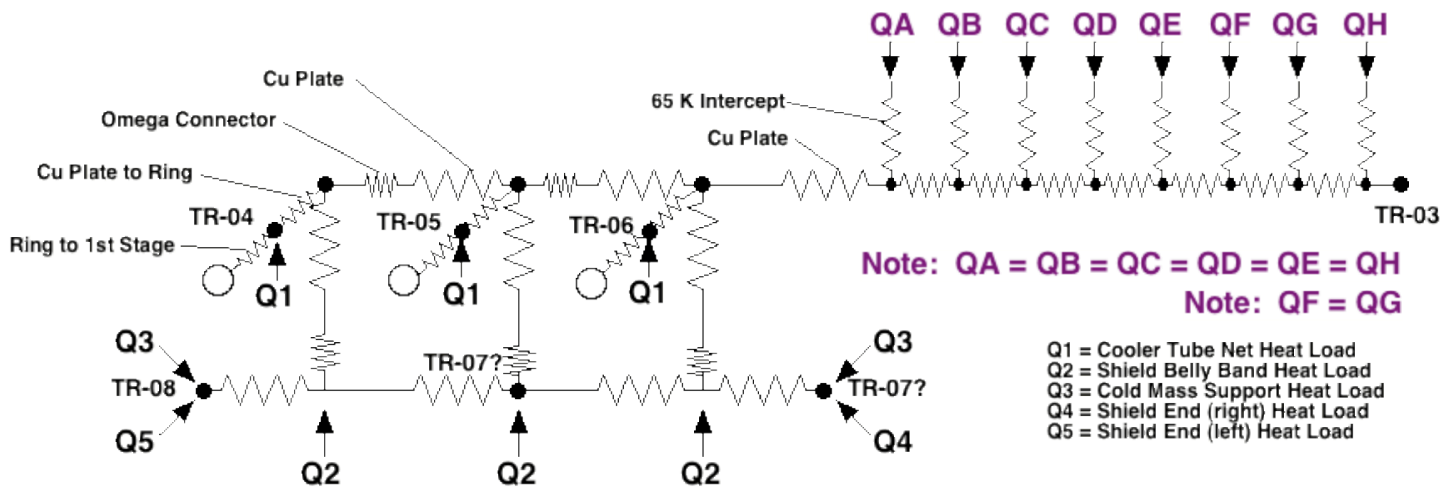

Figure 5. The Thermal Network for Stage-1 of Magnet 1A as Tested in 2008

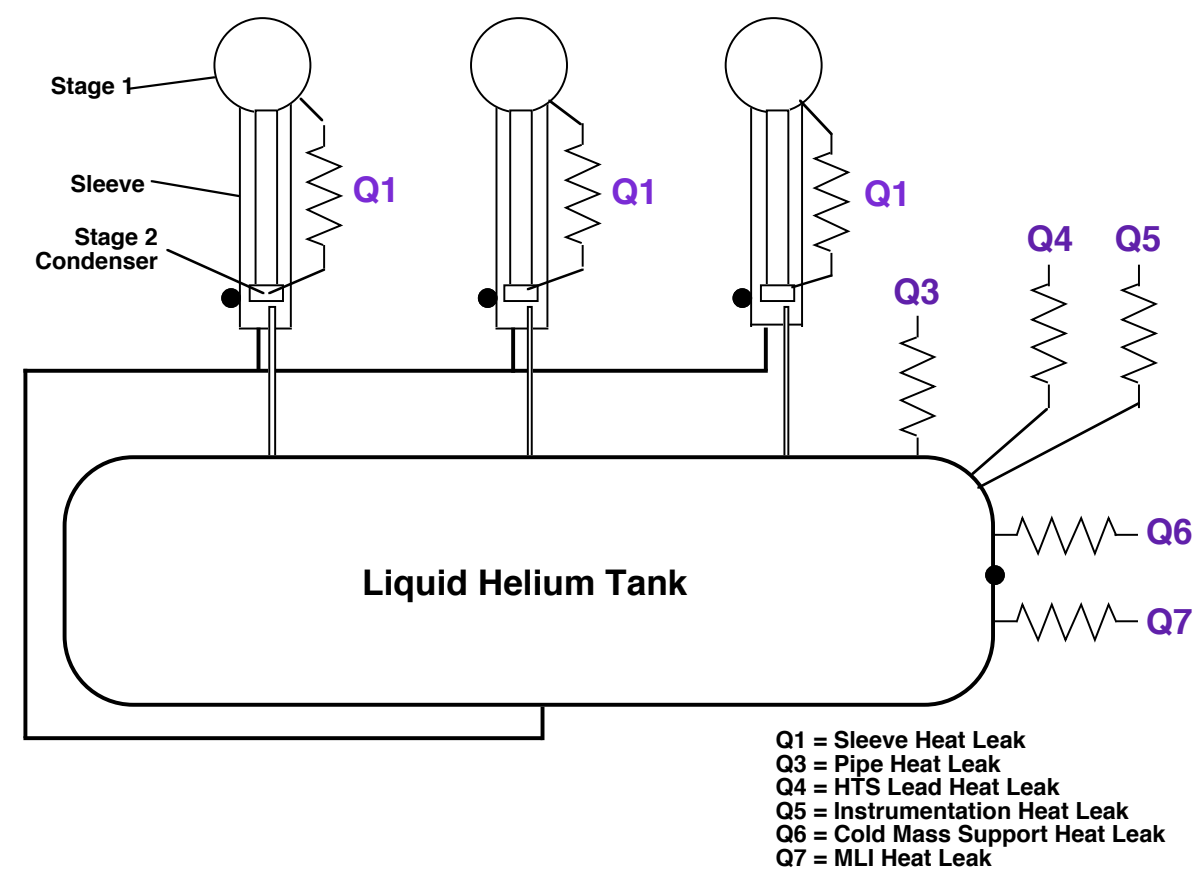

Figure 6. The Thermal Network for Stage-2 of Magnet 1A as Tested in 2008 (Note: the black dots represent the $4 \mathrm{~K}$ Silicon Diode sensors attached to the cold mass and the condenser cans.)

In figure 5, the value of $\mathrm{QH}=\sim 5 \mathrm{~W}$ and $\mathrm{QG}=\sim 1.5 \mathrm{~W}$, with no current in the leads. When there is current in the leads at full design current, $\mathrm{QH}=\sim 22 \mathrm{~W}$ and $\mathrm{QG}=\sim 6.5 \mathrm{~W}$. In figure 5, Q1 $=\sim 3 \mathrm{~W} ; \mathrm{Q} 2=\sim 13 \mathrm{~W} ; \mathrm{Q} 3=\sim 9 \mathrm{~W} ; \mathrm{Q} 4=\sim 54 \mathrm{~W}$ : and $\mathrm{Q} 5=\sim 54 \mathrm{~W}$. Q2, $\mathrm{Q} 4$, and Q5 are not well known, but the sum is about $121 \mathrm{~W}$. In Figure 6, Q1 $=\sim 0.3 \mathrm{~W}$; $\mathrm{Q} 3=\sim 0.2 \mathrm{~W} ; \mathrm{Q} 4=\sim 0.6 \mathrm{~W} ; \mathrm{Q} 5=\sim 0.4 \mathrm{~W} ; \mathrm{Q} 6=\sim 0.7 \mathrm{~W}$; and $\mathrm{Q} 7=\sim 2.9 \mathrm{~W}$. The value of Q7 is based on an 8 liter per hour net boil-off with no connection between the cold mass and the cooler second stage cold heads. This value of 8 liters per hour is hearsay, but this value makes sense given the other data we have. 


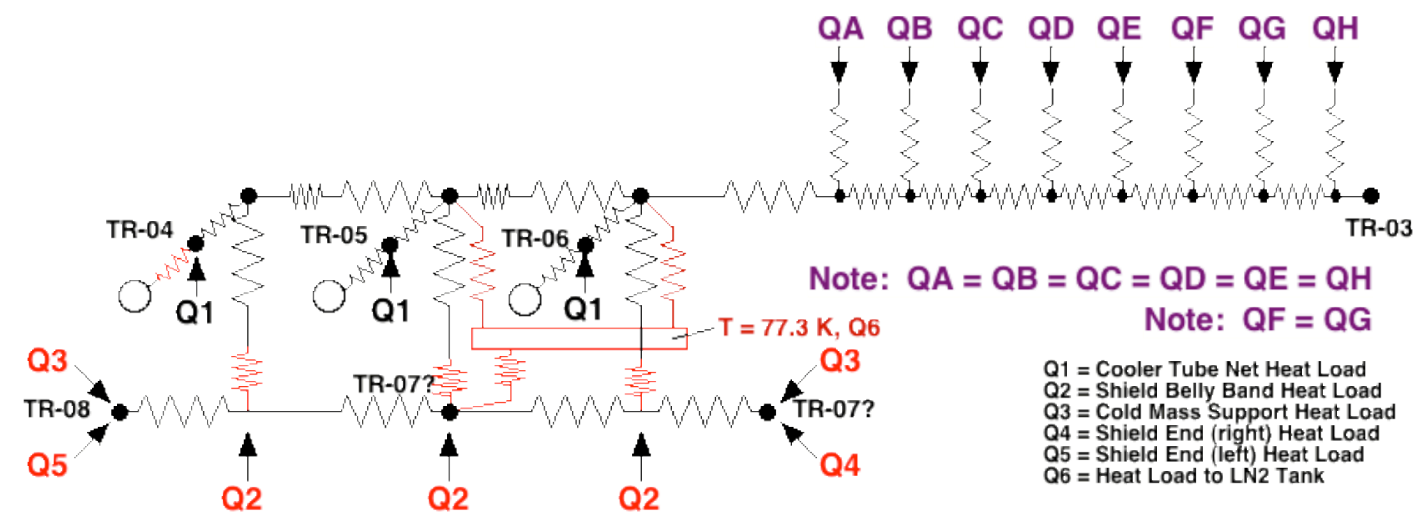

Figure 7. The Thermal Network for Magnet 2A as Tested in 2009

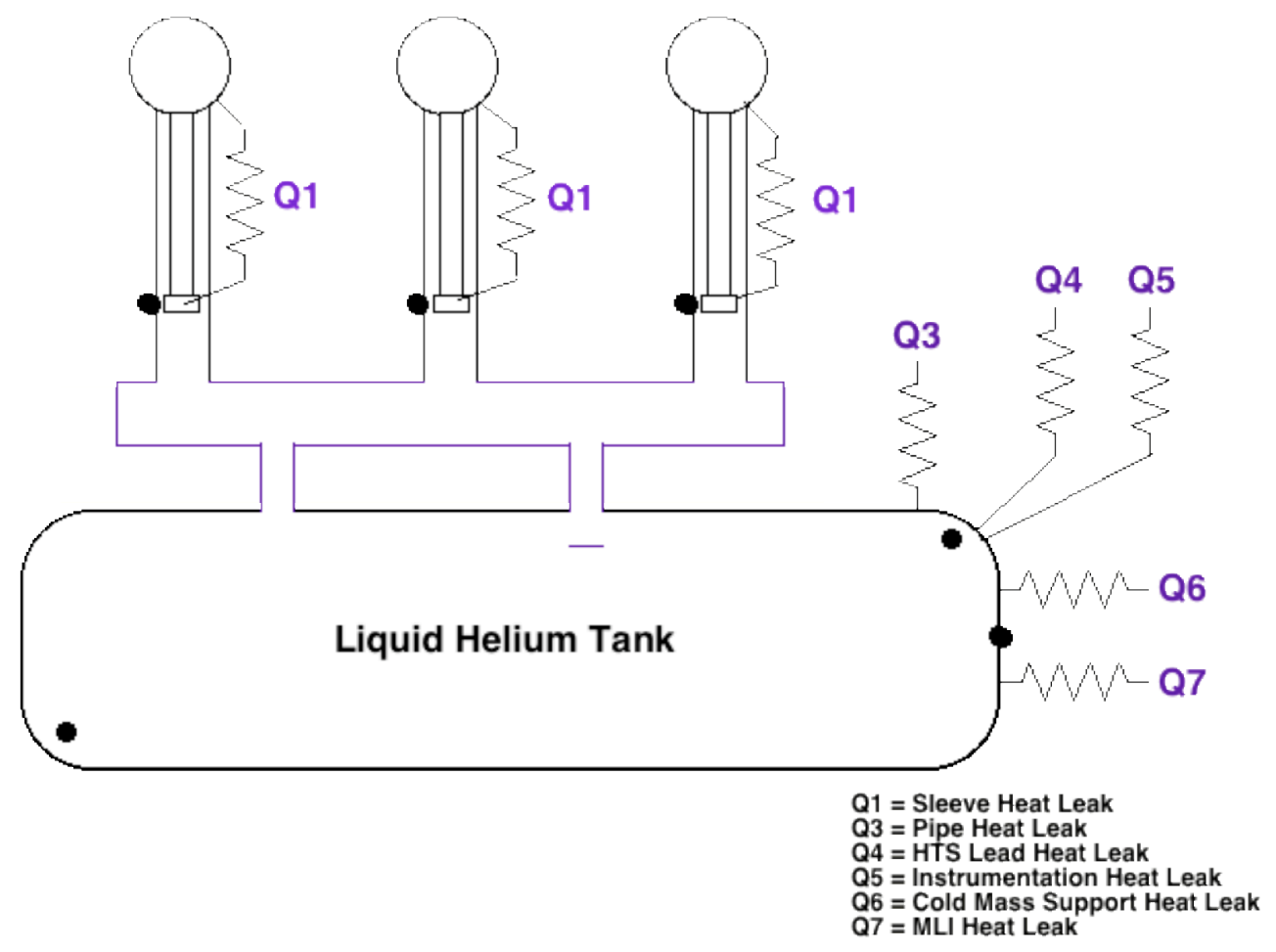

Figure 8. The Thermal Network for Stage-2 of Magnet 2A as Tested in 2009 (Note: the black dots represent the $4 \mathrm{~K}$ temperature sensors attached to the cold mass and the condenser cans.)

In figure 7, the value of $\mathrm{QH}=\sim 5 \mathrm{~W}$ and $\mathrm{QG}=\sim 1.5 \mathrm{~W}$, with no current in the leads. When there is current in the leads at full design current, $\mathrm{QH}=\sim 22 \mathrm{~W}$ and $\mathrm{QG}=\sim 6.5 \mathrm{~W}$. In figure 7, Q1 = 3 W; Q2 = 23 W; Q3 = 9 W; Q4 = 94 W: and Q5 = $94 \mathrm{~W} . \mathrm{Q} 2$, $\mathrm{Q} 4$, and Q5 are not well known, but the sum is about $211 \mathrm{~W}$. In Figure 8, Q1 $=\sim 0.3 \mathrm{~W}$; $\mathrm{Q} 3=\sim 0.3 \mathrm{~W} ; \mathrm{Q} 4=\sim 1.1 \mathrm{~W} ; \mathrm{Q} 5=\sim 0.4 \mathrm{~W}$; and $\mathrm{Q} 6=\sim 0.9 \mathrm{~W}$. According to the vendor, the net heat load into the cold mass would boil-off 3 liters per day. This must be considered to be hearsay that makes no sense in terms of the other data we have. Since the total heat leak to the cold mass is unknown and Q7 is also unknown. 


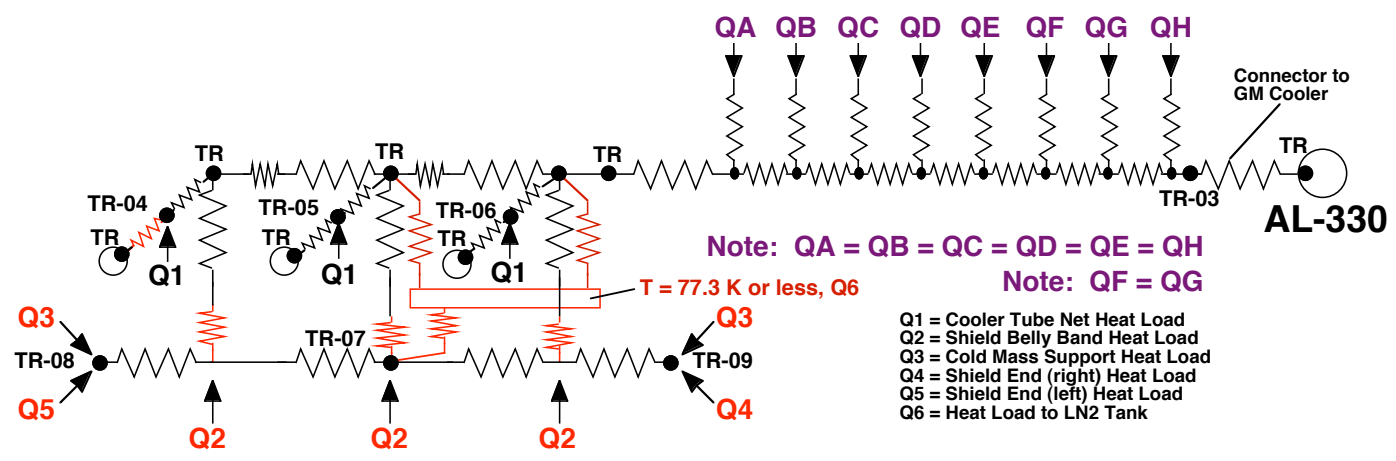

Figure 9. The Thermal Network for Magnet 2B as Tested in 2009

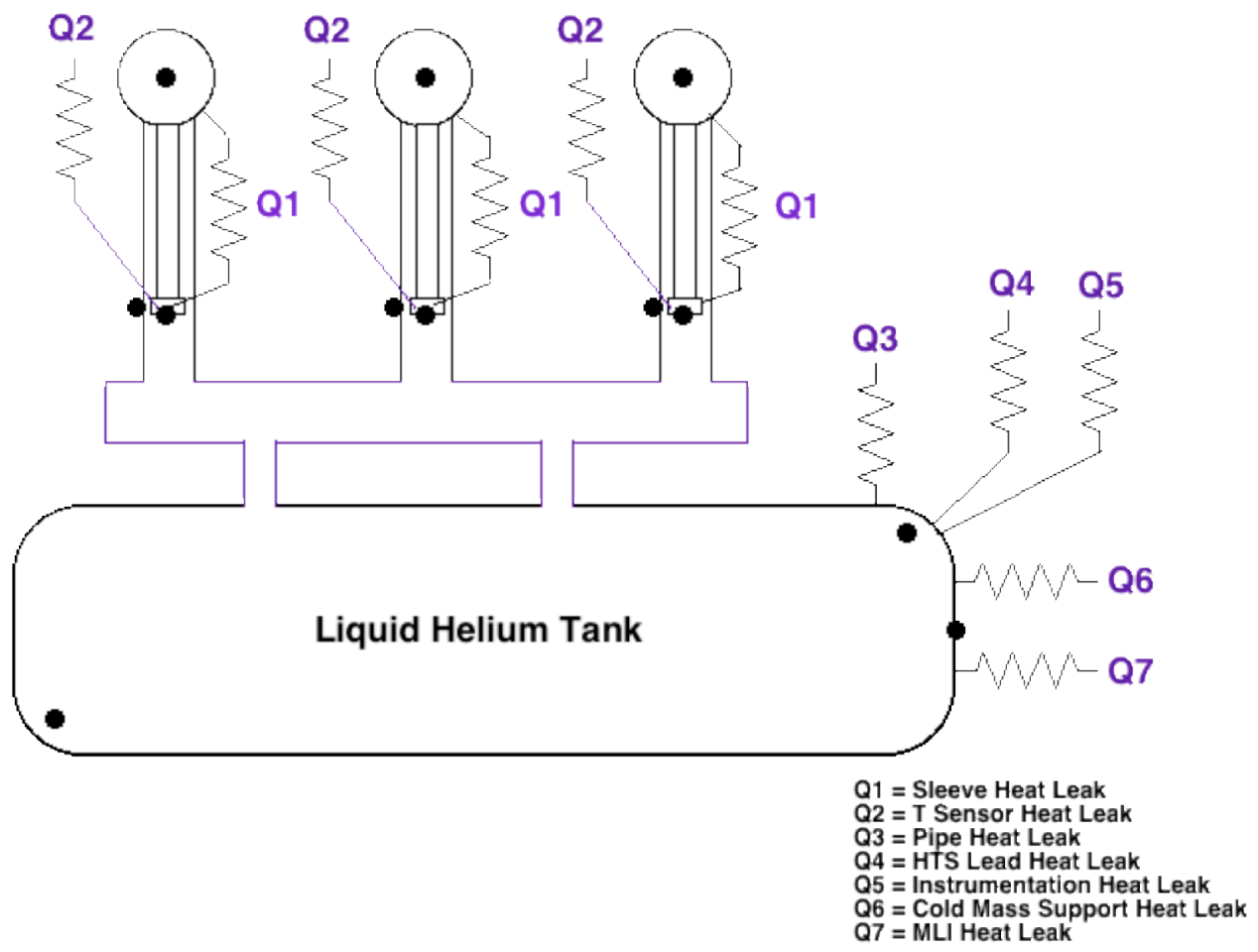

Figure 10. The Thermal Network for Stage-2 of Magnet 2A as Tested in 2009 (Note: the black dots represent the $4 \mathrm{~K}$ temperature sensors attached to the cold mass and the condenser cans.)

In figure 9, the value of $\mathrm{QH}=\sim 9 \mathrm{~W}$ and $\mathrm{QG}=\sim 2 \mathrm{~W}$, with no current in the leads. When there is current in the leads at full design current, $\mathrm{QH}=\sim 11.5 \mathrm{~W}$ and $\mathrm{QG}=\sim 5 \mathrm{~W}$. In figure 9, $\mathrm{Q} 1=\sim 3 \mathrm{~W} ; \mathrm{Q} 2=\sim 22 \mathrm{~W} ; \mathrm{Q} 3=\sim 9 \mathrm{~W} ; \mathrm{Q} 4=\sim 88 \mathrm{~W}$ : and $\mathrm{Q} 5=\sim 88 \mathrm{~W}$, without current in the leads. Q2, Q4, and Q5 are not well known, but the sum is about $198 \mathrm{~W}$. In Figure 10, Q1 = 0.3 W; Q2 = 0.2 W; Q3 = $0.3 \mathrm{~W} ; \mathrm{Q} 4=\sim 0.5 \mathrm{~W} ; \mathrm{Q} 5=\sim 0.4$ $\mathrm{W}$; $\mathrm{Q} 6=\sim 0.7 \mathrm{~W}$ and $\mathrm{Q} 7=\sim 3 \mathrm{~W}$. This is without current in the leads. The value of Q7 may actually be lower than indicated, if the connection between the magnet and the coolers is inefficient. Despite there being a possible resistive loss in the HTS leads, current in the magnet does not appear to have much effect on the net heat leak into the magnet. The effect of current in the leads is difficult to determine because the time constants are long. 


\section{Recommended Changes for Improving the Spectrometer Solenoid}

The author recommends that the following steps be taken to both reduce heat leak into the cold mass and improve the cooler efficiency at cooling the load:

1. The copper plate and turret should be extended to cover the vent tube region. This will reduce the heat leak to the cold mass through the vent and fill tubes.

2. The helium vent tubes and the helium should be firmly attached to the copper shield. This will reduce the $4 \mathrm{~K}$ heat leak somewhat.

3. The helium vent tubes should be bent above the shield to prevent direct radiation from $300 \mathrm{~K}$ from going into the $4 \mathrm{~K}$ region. This should also reduce the heat leak to $4 \mathrm{~K}$.

4. Possible sources of thermal acoustic oscillations must be eliminated. One way of doing this is to put a low-temperature check valve in the helium fillline and the main vent line. The vent line check valve must be large enough to permit full flow during a quench.

5. The shield should be extended to cover the parts of the cold mass support bands that extend beyond the large 6061-aluminum shield. The cans that contain the cold mass supports appeared to be slightly cooler where these cans connect to the main vacuum vessel. We note that this is easier said than done, however.

6. The connection between the large aluminum shield and the first stages of the two stage coolers must be improved to bring the shield and the cold mass support intercept temperature down further. This is already being done on magnet 1.

7. The tube between the condenser and the helium tank should go directly into the helium tank. The manifold between the helium tank and the coolers may interfere with the re-condensation of the magnet boil-off gas. This has already been done on magnet 1 for four coolers, but more work would be needed to accommodate a fifth 2 -stage cooler.

8. We should determine whether the apparent $\mathrm{I}^{2} \mathrm{R}$ heating in the HTS leads is real. This means that we should run the cooler and lead test again with added voltage taps to determine the source of the apparent $I^{2} R$ in the HTS leads. The vendor HTS- 110 will be contacted to see whether $I^{2} R$ heating in the HTS leads has been observed by others.

The author recommends the following steps be taken to reduce the heat leak into the the shields and improve the temperature uniformity of the shield:

9. Magnet 2 must be disassembled in order to determine the cause of the added heat leak onto the magnet shield and by implication the first-stages of the coolers. This is necessary because five two stage coolers will provide less cooling than three two stage coolers plus one Al-330 single stage cooler.

10. The effective thermal conductivity between the aluminum shield and the copper plate that connects the cooler first-stages must be increased to bring the shield temperature down. Doing this will also reduce the heat flow into the cold mass. This change is already being made on Magnet 1 . 
11. The thermal conductivity along the shield should be improved so that the cold mass intercepts run colder. Doing this will also reduce the heat flow into the cold mass. This change is already being made on Magnet 1.

12. A provision should be made to allow a single stage to be added if needed. This change is being considered.

The heat leak into the magnet 2 shield from all other sources except the leads appears to be almost unchanged between tests $2 \mathrm{~A}$ and $2 \mathrm{~B}$. The heat flow into the shield of magnet 1 is lower than it was for both configurations of magnet 2 . It appears that the source of the added he is within the main vacuum vessel of the magnet. The turret appears to be a small contributor to the added heat leak in magnet 2 as compared to magnet 1 . There are a lot of unanswered questions as to what happened with magnet $2 \mathrm{~B}$. We will know more about what happened with magnet 2 when the magnet cryostat and perhaps the cold mass are disassembled.

\section{Acknowledgment}

This work was also supported by the Office of Science of the US Department of Energy under DOE contract DE-AC-02-05CH11231.

\section{References}

[1] G. Gregoire, G. Ryckewaert, L. Chevalier, et al, "MICE and International Muon Ionization Experiment Technical Reference Document," http://www.mice.iit.edu, (2001).

[2] P. Fabbricatore, S. Farinon, M. Perrella, et al. "The Mechanical and Thermal Design for the MICE Detector Solenoid Magnet System, IEEE Transactions on Applied Superconductivity 15, No. 2, p 1255, (2005).

[3] M. A. Green, C. Y. Chen, T. Juang et al, "Design Parameters for the MICE Tracker Solenoid," IEEE Transactions on Applied Superconductivity 17, No. 2, p 1247, (2007).

[4] S. T. Wang, R. Wahrer, C. Taylor, et al, "The Design and Construction of the MICE Spectrometer Solenoids," IEEE Transactions on Applied Superconductivity 19, No. $3 \mathrm{p}$ 1348, (2009)

[5] S. P. Virostek, M. A. Green, et al, "Preliminary Test Results for the MICE Spectrometer Superconducting Solenoids," IEEE Transactions on Applied Superconductivity 19, No. 3 p 1364 (2009)

[6] S. P. Virostek, and M. A. Green, "The Results of Tests of the MICE Spectrometer Solenoids," to be published in IEEE Transactions on Applied Superconductivity 20, No. 3 (2010).

[7] S. P. Virostek, M. A. Green, F. Trillaud, and M. S. Zisman "Fabrication, Testing, and Modeling of the MICE Superconducting Spectrometer Solenoids," Proceedings of IPAC10, Kyoto Japan, 23 to 28 May 2010.

[8] Y. S. Choi, T. A. Painter, D. L. Kim, et al, "Helium-Liquefaction by Cryocooler for HighField Magnets Cooling, " Proceedings of the International Cryocooler Conference (2006)

[9] M. A. Green and S. T. Wang, "Tests of Four PT-415 Coolers Installed in the Drop-in Mode," co-authored with S. T. Wang, Proceedings ICEC-22 (2009)

[10] Private communication with S. T. Wang of Wang NMR concerning Figure 2.

[11] M. A. Green, "Results from Cooler Lead Tests," MICE Note-291 http://www.mice.iit.edu, (June 2010)

[12] “Single Stage Gifford-McMahon Cycle Cooler Performance Curves," Cryomech, 113 Falso Drive, Syracuse NY 13211, USA, http://www.cryomech.com 


\section{DISCLAIMER}

This document was prepared as an account of work sponsored by the United States Government. While this document is believed to contain correct information, neither the United States Government nor any agency thereof, nor The Regents of the University of California, nor any of their employees, makes any warranty, express or implied, or assumes any legal responsibility for the accuracy, completeness, or usefulness of any information, apparatus, product, or process disclosed, or represents that its use would not infringe privately owned rights. Reference herein to any specific commercial product, process, or service by its trade name, trademark, manufacturer, or otherwise, does not necessarily constitute or imply its endorsement, recommendation, or favoring by the United States Government or any agency thereof, or The Regents of the University of California. The views and opinions of authors expressed herein do not necessarily state or reflect those of the United States Government or any agency thereof, or The Regents of the University of California. 